\title{
Nonalcoholic steatohepatitis: the role of peroxisome proliferator-activated receptors
}

\author{
Sven Francque ${ }^{* 1,2 \dagger}$, Gyongyi Szabo*†3, Manal F. Abdelmalek ${ }^{4}$, Christopher D. Byrne ${ }^{5}$, \\ Kenneth Cusi ${ }^{6}$, Jean-François Dufour ${ }^{7,8}$, Michael Roden ${ }^{9-11}$, Frank Sacks ${ }^{12,13}$, Frank \\ Tacke $^{14}$
}

1. Department of Gastroenterology and Hepatology, Antwerp University Hospital, Antwerp, Belgium

2. Translational Research in Inflammation and Immunology $\left(T W I^{2} N\right)$, Faculty of Medicine and Health Sciences, University of Antwerp, Belgium

3. Beth Israel Deaconess Medical Center, Harvard Medical School, Boston, MA, USA

4. Division of Gastroenterology and Hepatology, Department of Medicine, Duke University Health System, Durham, NC, USA

5. Nutrition \& Metabolism, Human Development \& Health, Faculty of Medicine, University Hospital Southampton, Southampton, UK

6. Division of Endocrinology, Diabetes and Metabolism, University of Florida, Gainesville, FL, USA

7. Hepatology, Department of Clinical Research, University Hospital of Bern, Bern, Switzerland

8. University Clinic for Visceral Surgery and Medicine, Inselspital, Bern, Switzerland

9. Division of Endocrinology and Diabetology, Medical Faculty, Heinrich Heine University Düsseldorf, University Clinics Düsseldorf, Düsseldorf, Germany

10. Institute for Clinical Diabetology, German Diabetes Center (DDZ), Leibniz Center for Diabetes Research at Heinrich Heine University Düsseldorf, Düsseldorf, Germany

11. German Center for Diabetes Research (DZD e.V.), München-Neuherberg, Germany

12. Departments of Nutrition and Molecular Metabolism, Harvard T.H. Chan School of Public Health, Boston, MA, USA

13. Channing Division, Department of Medicine Harvard Medical School and Brigham and Women's Hospital, Boston, MA, USA

14. Department of Hepatology \& Gastroenterology, Charité University Medical Center, Berlin, Germany

* These authors contributed equally to this work.

\section{†email: gszabo1@bidmc.harvard.edu; sven.francque@uza.be}

\section{TOC blurb}

This Review describes the pathophysiological roles of peroxisome proliferator-activated receptors (PPARs) in nonalcoholic steatohepatitis (NASH) and related metabolic diseases, and summarizes the preclinical and clinical data on the use of PPAR agonists to treat NASH as part of a systemic metabolic disease.

\footnotetext{
Abstract

The increasing epidemic of obesity abound the world is linked to serious health effects, including increased prevalence of type 2 diabetes mellitus, cardiovascular disease and nonalcoholic fatty liver disease (NAFLD). NAFLD is the liver manifestation of the metabolic syndrome and includes the spectrum of liver steatosis (known as nonalcoholic fatty liver) and steatohepatitis (known as nonalcoholic steatohepatitis), which can evolve into progressive liver fibrosis and eventually cause cirrhosis. Although NAFLD is becoming the number one cause of chronic liver diseases, it is part of a systemic disease that affects many other parts
} 
of the body, including adipose tissue, pancreatic $\beta$-cells and the cardiovascular system. The pathomechanism of NAFLD is multifactorial across a spectrum of metabolic derangements and changes in the host microbiome that trigger low-grade inflammation in the liver and other organs. Peroxisome proliferator-activated receptors (PPARs) are a group of nuclear regulatory factors that provide fine tuning for key elements of glucose and fat metabolism, and regulate inflammatory cell activation and fibrotic processes. This Review summarizes and discusses the current literature on NAFLD as the liver manifestation of the systemic metabolic syndrome and focuses on the role of PPARs in the pathomechanisms, as well as in the potential targeting, of disease.

\section{[H1] Introduction}

With an estimated global prevalence of $25 \%{ }^{1}$, nonalcoholic fatty liver disease (NAFLD) is defined by evidence of steatosis in $\geq 5 \%$ of hepatocytes according to histological analysis or imaging in the absence of secondary causes of hepatic fat accumulation such as clinically significant alcohol consumption ${ }^{2,3}$. NAFLD can be subdivided into nonalcoholic fatty liver (NAFL) and nonalcoholic steatohepatitis (NASH). NASH is characterized by hepatic steatosis accompanied by lobular inflammation and ballooned hepatocytes (as a marker of hepatocyte injury), with or without hepatic fibrosis, whereas NAFL is defined as hepatic fat content of $\geq 5 \%$ of liver weight or $\geq 5 \%$ fat-loaded hepatocytes with no evidence of hepatocellular injury (namely, ballooning) or fibrosis. ${ }^{2,3}$ An estimated $10-25 \%$ of patients with NAFLD have NASH, and up to $25 \%$ of patients with NASH progress to cirrhosis, liver failure and, more rarely, hepatocellular carcinoma $(\mathrm{HCC})^{3,4}$. By the end of $2020, \mathrm{NASH}$ is expected to be the leading cause of liver transplantation in the United States ${ }^{5}$, and NAFLD-related mortality and morbidity in terms of advanced liver disease will more than double from 2016 to $2030^{6}$.

NAFLD is part of a multisystem disease with ramifications that extend beyond the liver ${ }^{7}$. Morbidity and mortality are also related to the effect of the diseased liver on the cardiovascular system ${ }^{8}$ and on organs involved in glycaemic control. Patients with NAFLD are two to five times more likely to develop type 2 diabetes mellitus (T2DM) after adjustment for multiple confounders than those without NAFLD ${ }^{9,10}$, and NAFLD can add to coexisting metabolic risk factors ${ }^{11}$. Conversely, patients with T2DM are also at a high risk of NAFLD: the global prevalence of NAFLD among patients with T2DM exceeds $55 \%{ }^{12}$.

The liver is involved in the pathogenesis of the metabolic syndrome (Table 1), or components of the metabolic syndrome, which frequently occurs in $>50 \%$ of patients with NAFLD ${ }^{13,14}$. The liver is a key organ that is affected by nutritional overload (so-called substrate-overload liver injury), adipose tissue dysfunction, insulin resistance and gut dysbiosis ${ }^{15}$. The role of liver disease in the pathogenesis of T2DM and cardiovascular disease (CVD) shows that it is a driving force of a vicious circle ${ }^{16,17}$. For example, NAFLD increases the risk of T2DM ${ }^{18}$ and $C V D^{19}$. With the development of T2DM, there is a further increase in risk of CVD ${ }^{20,21}$, a worsening of liver disease (to fibrosis and cirrhosis) ${ }^{22-24}$ and an increased risk of $\mathrm{HCC}^{25}$. The development of advanced liver fibrosis with NAFLD also increases the risk of CVD ${ }^{26}$. Figure 1 illustrates the relationships between NAFLD, T2DM and the metabolic syndrome, CVD and HCC.

Lifestyle interventions that lead to weight loss are recommended for the treatment of $\mathrm{NASH}^{2,3}$, but these interventions are difficult to sustain and are not even always sufficient (Box 1). Currently, the only commercially available pharmacological options for NASH supported by clinical trials with histological endpoints are vitamin $\mathrm{E}$ and pioglitazone (and to a lesser extent liraglutide), but these are not approved by the Food and Drug Administration (FDA) for the treatment of NAFLD ${ }^{27-29}$. Therefore, there is a search for treatments across a 
broad spectrum of new pharmacological agents that have a plethora of mode of actions and that target a variety of pathways (previously reviewed ${ }^{30,31}$ ). Of particular interest are peroxisome proliferator-activated receptors (PPARs) because they are key regulators of lipid and glucose metabolism, as well as of inflammation in different tissues. Their differential expression and role in the liver as well as in the adipose tissue, skeletal muscle, vessel wall and pancreas make them highly relevant to NAFLD when it is considered part of a systemic metabolic disease ${ }^{32}$. Thus, PPARs represent interesting therapeutic targets both in a livercentred approach as well as in a systemic approach to NAFLD, in terms of improving liver function and liver, cardiovascular and diabetes-related outcomes. This Review aims to comprehensively summarize the current pre-clinical and clinical knowledge on the varied roles of PPARs in the pathophysiology of NASH when viewed as an integrated part of metabolic and cardiovascular derangements, a framework that must serve as a rationale for their use in the treatment of this condition. Thus, this Review examines the pivotal elements in the pathogenesis of NASH (taking into account the systemic disease approach), the role of PPARs as key regulators of fatty acid metabolism, inflammation and fibrosis in the liver and in extrahepatic tissues, and the potential therapeutic advantages of the wide-ranging actions of PPAR agonists in the systemic ramifications of NAFLD.

\section{[H1] Clinical implications of NAFLD}

NAFLD is one part of the consequences of caloric overload and sedentarism and is therefore commonly referred to as the hepatic manifestation of the metabolic syndrome, a cluster of cardiovascular risk factors that include central obesity, increased plasma glucose and triglyceride concentrations, decreased high-density lipoprotein cholesterol (HDL-C) concentration, increased blood pressure and central obesity, which is therefore a very common condition in adults with NAFLD, with a prevalence of $>50 \%$ in patients with NASH and significant fibrosis ${ }^{1,7,11,33}$. The relationships are multidirectional, with NAFLD being in part both the consequence and cause of metabolic and cardiovascular derangements. Adipose tissue dysfunction has been identified as an important driver of disease in a multisystem 'metabolic' disorder in which the liver, pancreas, muscle, gut and the cardiovascular system are implicated in a complex crosstalk ${ }^{15,34}$. Established T2DM in adults with NAFLD is a strong clinical risk factor for the more progressive forms of NAFLD, such as NASH with fibrosis $7,11,33$. Insulin resistance occurs in almost all adults $7,11,33$ and children ${ }^{35,36}$ with NAFLD. T2DM occurs in approximately $70 \%$ of patients with NAFLD ${ }^{33}$, and a 2016 study reported that the prevalence of prediabetes and T2DM was $23.4 \%$ and $6.5 \%$, respectively, in children and adolescents with obesity and biopsy-confirmed $\mathrm{NASH}^{37}$. This close entanglement between fatty liver disease and metabolic derangements have led to a proposal by a group of experts to redefine and rename NAFLD as metabolic (dysfunction)-associated fatty liver disease (MAFLD), and although this terminology has not yet been widely approved, it reflects the growing understanding of NAFLD as being part of this multisystem disorder of largely overlapping 'metabolic' conditions ${ }^{38}$.

Consequently, current European Association for the Study of the Liver (EASL) 2 and American Association for the Study of Liver Diseases (AASLD) ${ }^{3}$ guidelines recommend that patients with NAFLD be thoroughly investigated for these comorbid conditions. Components of the metabolic syndrome and cardiovascular risk factors have to be checked and treated according to their proper guidelines (Table 1).

The concept of NAFLD being part of a metabolic multisystem disease implies that patients with NAFLD need not only a liver-centred approach, but also in parallel a multidisciplinary approach. When it comes to specific therapies, these aspects also come into play. Evidently, therapies need to be safe from a metabolic and cardiovascular point of view ${ }^{39}$. The effect on these different co-morbid conditions of different pharmacological approaches (which are to 
some extent artificially split into anti-metabolic, anti-inflammatory and anti-fibrotic strategies ${ }^{31}$ ) will potentially become increasingly important, not only in terms of safety but also in terms of efficacy. Compounds that target not only the intrahepatic processes of damage, inflammation and fibrogenesis, but that also have an effect on systemic inflammation, metabolic factors and the cardiovascular system might result in a greater overall improvement in outcomes compared with compounds with a more liver-restricted mode of action. Another consideration that emerges from this systemic approach is the growing awareness that part of the hepatic improvement observed with pharmacological treatment is an indirect result of extrahepatic inflammatory and metabolic improvements that subsequently benefit the liver ${ }^{30,31}$. Thus, this holistic, systemic approach towards NAFLD is relevant to the identification of suitable targets for pharmacological treatment of NAFLD and NASH.

\section{[H1] Key mechanisms of NASH pathophysiology}

In this section, we describe the key mechanisms involved in the development of insulin resistance and hepatic lipid accumulation, dyslipidaemia and inflammation that are part of the pathogenesis of NASH.

\section{[H2] Insulin resistance}

Insulin resistance can result from certain inherited factors but mainly from acquired factors such as obesity and specifically ectopic fat accumulation in visceral organs such as liver ${ }^{15}$. Insulin resistance is primarily characterized by increased lipolysis in dysfunctional adipose tissue and reduced glucose uptake in skeletal muscle ${ }^{9,40}$. Adipose tissue dysfunction comprises local inflammation and impaired anti-lipolytic action of insulin, resulting in an increased release of free fatty acids (FFA) and glycerol ${ }^{40,41}$. Higher hepatic uptake of FFA contributes via fatty acid esterification, while glucose uptake contributes to a lesser extent via de novo lipogenesis, to accumulation of triglycerides in liver and VLDL release, and thereby paves the way to steatosis (NAFL) and dyslipidaemia ${ }^{42}$. Increases in hepatic lipid metabolites, such as diacylglycerols and ceramides, interfere with insulin signalling and thereby lead to hepatic insulin resistance ${ }^{9,40,43}$. Insulin resistance is strongly associated with NAFLD, but its correlation with NASH severity is still unclear ${ }^{44}$. Three-quarters of people with obesity and T2DM have NAFLD ${ }^{45}$, but it is unclear whether liver fat accumulation is a consequence or cause of insulin resistance. Nevertheless, increased delivery of plasma FFA from adipose tissue to the liver accounts for $\sim 60 \%$ of all fatty acid incorporation into liver triglyceride ${ }^{41,42}$, underlining the important role of adipose tissue in hepatic lipid accumulation, insulin resistance and increased VLDL secretion, therefore linking the pathogenesis of NASH to a key aspect of the atherogenic dyslipidaemia of metabolic syndrome (see later).

The development of hepatic damage in people with NASH requires both extrahepatic and intrahepatic factors, which highlights the involvement of multiorgan systems in the disease. Chronic adipose dysfunction creates an imbalance between the release of anti-inflammatory insulin-sensitizing cytokines (such as adiponectin) and pro-inflammatory cytokines (such as interleukin-6 (IL-6) and tumour necrosis factor (TNF)) that activate inflammatory pathways and contribute to insulin resistance in the liver ${ }^{46}$.

\section{[H2] Lipid metabolism and lipotoxicity in NASH}

Lipotoxicity caused by lipid metabolites (such as diacylglycerols, ceramides and acylcarnitines) is generally thought to have a central role in the pathogenesis of NASH ${ }^{41,47-49}$. According to the substrate-overload liver injury model of NASH pathogenesis, the liver's capacity to handle the primary metabolic energy substrates, carbohydrates and fatty acids, is overwhelmed in $\mathrm{NASH}$, leading to an accumulation of toxic lipid species ${ }^{50}$. In hepatocytes, fatty acids are metabolized via mitochondrial $\beta$-oxidation, or undergo re-esterification into 
triglycerides that are then exported from the liver as VLDL or stored in hepatic lipid droplets. The latter undergo lipolysis and release fatty acids back into the hepatocyte FFA pool ${ }^{15,41,42}$. Excess accumulation of fatty acids leads to the formation of lipotoxic species, resulting in endoplasmic reticulum stress, oxidant stress and inflammasome activation. ${ }^{9,40,51}$

NAFLD is defined by an accumulation of triglycerides in the liver. This accumulation of liver triglycerides can occur for several different reasons, and the sources of fatty acids that are required for the generation of hepatic triglycerides are principally derived from adipose tissue $^{52,53}$. For example, it has been estimated that of the triglycerides accounted for in the human liver, $59.0 \% \pm 9.9 \%$ arise from adipose tissue-generated FFAs, $26.1 \% \pm 6.7 \%$, from hepatic de novo lipogenesis, and $14.9 \% \pm 7.0 \%$ from the $\operatorname{diet}^{54}$. Consequently, with increasing adipose tissue mass and specifically with the accumulation of dysfunctional and insulin-resistant adipocytes, release of FFA to the liver provides the substrate for and stimulus to hepatic lipid accumulation, leading to insulin resistance, atherogenic dyslipidaemia, T2DM, atherosclerosis and increased CVD risk ${ }^{47,55,56}$. In addition, activated adipose tissue macrophages are also important in promoting adipose tissue insulin resistance, excess lipolysis and FFA release from adipocytes, and subsequent liver fat deposition. ${ }^{57}$

\section{[H2] Inflammation in NASH}

$\mathrm{NASH}$ is characterized by inflammation superimposed on hepatic steatosis, but inflammation is also present in other organs, which once again indicates systemic involvement ${ }^{58}$. Inflammation is the innate immune system's response to invading pathogens and to sterile tissue injury. In normal homeostasis, anti-inflammatory cytokines and natural tissue repair mechanisms resolve inflammation. In NASH, however, the sustained presence of metabolic danger signals maintains inflammation ${ }^{59-61}$. Multiple sequential and parallel triggers contribute to inflammation and create self-perpetuating low-grade hepatic and systemic inflammation ${ }^{58}$.

Well-characterized triggers of liver inflammation include sterile danger signals such as saturated fatty acids and oxidized cholesterol, which cause lipotoxicity in hepatocytes, apoptosis and other types of hepatocellular death ${ }^{62}$. Alteration of intracellular signalling pathways during inflammation affects nuclear receptors such as PPARs, nuclear factor- $\kappa B$ $(N F-\kappa B)$ activation and microRNAs ${ }^{63}$. Damaged hepatocytes in turn release other sterile metabolic danger signals, including uric acid, high mobility group box 1 (HMGB1) and mitochondrial DNA, which activate a variety of pattern recognition receptors and trigger

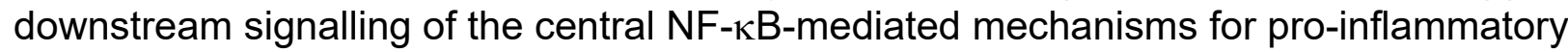
cytokine and chemokine production, and macrophage activation ${ }^{59-62,64,65}$.

Abnormalities in the gut-liver axis have also been linked to NAFLD and NASH. For example, the importance of an altered gut microbiota has been extensively studied in NASH ${ }^{66,67}$. Increased gut permeability due to inflammation in the intestinal wall results in increased levels of pathogen-associated molecular patterns in the systemic circulation and liver ${ }^{68}$.

\section{[H2] Immune cells in the development of NASH}

Activation of Kupffer cells, the liver's resident macrophages, in combination with recruitment of pro-inflammatory, monocyte-derived macrophages and neutrophil leukocytes from the circulation, characterize NASH-related changes in the immune cell populations of the liver ${ }^{59,65}$. Parallel to the strong accumulation of macrophages, their polarization appears 'proinflammatory' (often termed M1) at the expense of anti-inflammatory and repair macrophages (often termed M2), likely due to the high abundance of pro-inflammatory cytokines such as interferon- $\gamma$, TNF and lipopolysaccharide (LPS) in NASH ${ }^{62}$ However, the classical M1/M2 paradigm does not fully capture hepatic macrophage populations in NAFLD, as the resident 
and recruited macrophages rapidly and precisely adapt to the hepatic environment both in mice and humans ${ }^{69,70}$. Single-cell RNA sequencing analyses of mouse models of NASH have indeed revealed a common and unique inflammatory 'NAFLD phenotype' that is consistent across myeloid cells (monocytes, macrophages and dendritic cells) in the liver as well as in the bone marrow ${ }^{71}$. These inflammatory myeloid cells perpetuate hepatic inflammation, leading to hepatocyte death, activation of hepatic stellate cells (HSCs) and myofibroblasts that drive fibrogenesis, progressive liver damage, inflammation and fibrosis in NASH ${ }^{61,65}$. Importantly, PPAR $\gamma$ and PPAR $\beta / \delta$ activation (these isotypes are described in the next section) is a trigger for anti-inflammatory or repair-promoting macrophage polarization ${ }^{72}$. Pharmacological PPAR $\beta / \delta$ agonism reduced NAFLD-associated inflammatory macrophage activation in mouse models as well as in circulating monocytes from patients with $\mathrm{NASH}^{73}$.

\section{[H1] PPARs: metabolic pathway regulators}

PPARs were first described as members of the steroid hormone receptor superfamily of ligand-activated transcription factors that cause proliferation of peroxisomes ${ }^{74,75}$.

Peroxisomes have an important role in fatty acid catabolism and in the pentose phosphate pathway, and hence in energy metabolism. They also have a role in the reduction of ROS $^{76}$. However, extensive research has subsequently revealed that PPAR signalling pathways involve several other cell organelles, most notably mitochondria, and that PPARs have pleiotropic actions, which ultimately makes them critical regulators not only of fatty acid metabolism ${ }^{74}$, but also of glucose metabolism, inflammation and fibrogenesis ${ }^{74}$.

Three PPAR isotypes have been identified $-\alpha, \beta / \delta$ and $\gamma$ (with two subtypes: $\gamma 1$ and $\gamma 2)^{77,78}$ — the expression and actions of which differ according to isotype, organ and intraorgan cell type, resulting in a complex system of nuclear receptor-mediated inter-organ crosstalk $^{79}$ (Figure 2). Furthermore, substantial inter-species differences exist and need to be taken into account to translate findings from pre-clinical studies to patients ${ }^{76}$. The importance of inter-species differences has best been documented for PPAR $\alpha$. Although latest reports indicate that human and mice liver PPAR $\alpha$ expression is comparable (in contrast to previous reports suggesting a lower PPAR $\alpha$ expression in human liver), PPAR $\alpha$ activity has been repeatedly shown to be lower in human livers compared with rats and mice ${ }^{80-83}$. Also, differences between murine and human, but also guinea pig livers, have been found at the level of PPARa expression, ligand activation and biological response ${ }^{84}$. This interspecies difference is particularly relevant when it comes to the role of peroxisome proliferation and tumorigenesis (and hence safety of PPAR $\alpha$-targeting drugs, which has been demonstrated in rats and mice, whereas PPAR $\alpha$ activation failed to induce peroxisome-proliferator genes in human hepatocytes) ${ }^{85-87}$. PPAR $\gamma$ is more conserved across species than PPAR $\alpha$, although some differences, for example in brown adipose tissue, have been documented ${ }^{88,89}$. Liver PPAR $\gamma$ expression, which is low compared with adipose tissue expression, is induced by obesity in mice (specifically, the $\gamma 2$ subtype ${ }^{90}$ ), but no increased expression has been observed in human liver in relation to $\mathrm{NASH}^{91}$.

\section{[H2] Steatosis and beyond}

The main ligands for PPARs are fatty acids and their metabolites. Endogenous ligands can result from lipogenesis, lipolysis and fatty acid catabolism, which explains the reciprocal effects between, for example, PPAR $\alpha$ pathways and acyl-CoA oxidase 1 (implicated in peroxisomal $\beta$-oxidation), fatty acid synthase (FAS, implicated in de novo lipogenesis) or hepatic adipose triglyceride lipase (implicated in triglyceride hydrolysis) ${ }^{92-94}$.

PPAR $\alpha$, which is encoded by NR1C1 on human chromosome 22, binds to a wide range of saturated and unsaturated fatty acids, whereas the other PPAR isotypes have a lower 
affinity that is mainly restricted to polyunsaturated fatty acids ${ }^{95}$. PPAR $\alpha$ is predominantly expressed in tissues with a high rate of fatty acid oxidation, such as skeletal muscle, liver, heart, kidney and brown adipose tissue ${ }^{79,96}$. Within the liver, it is expressed mainly in hepatocytes ${ }^{79,91,97}$. In the vasculature, it is also expressed in various cell types within atherosclerotic plaques ${ }^{98}$. Notably, within the liver, expression has also been documented in sinusoidal endothelial cells and, at a lower level of expression, also in mice and human HSCs, which are maintained in the quiescent state by PPAR $\alpha^{99-102}$.

As a key regulator of fatty acid metabolism and ketogenesis, PPAR $\alpha$ regulates fatty acid transport, peroxisomal and mitochondrial $\beta$-oxidation and lipolysis, and also influences the production of apolipoproteins ${ }^{103}$. The net overall result of PPAR $\alpha$-mediated lipid handling leads to a reduction of triglyceride-rich lipoproteins and triglyceride accumulation in the liver, whereas plasma HDL cholesterol (HDL-C) is increased ${ }^{103}$. In the fasting state, increased fatty acid oxidation produces acetyl-CoA, which is then converted into ketone bodies in a process involving mitochondrial hydroxymethylglutaryl-CoA synthase (HMGCS), which is upregulated by PPAR $\alpha^{104}$. PPAR $\alpha$-deficient mice fed ad libitum have a mild phenotype, but the phenotype becomes more pronounced during fasting and is characterized by impaired fatty acid oxidation, lipid accumulation in the liver as well as an inability to augment ketone body synthesis, which indicates that PPAR $\alpha$ is critically involved in the fasting state ${ }^{105}$. Transcriptomic studies in PPAR $\alpha$-deficient mice in a fasting or fed condition have confirmed that major changes in expression of its main target genes involved in fatty acid transport and catabolism, including peroxisomal and mitochondrial $\beta$ oxidation, in the liver occur in the fasting state ${ }^{106}$. Furthermore, PPAR $\alpha$ seems to be implicated in the circadian clock $^{107-111}$. It also regulates expression of a plethora of target genes by transactivation or transrepression (transrepression refers to the process of interaction with another nuclear factor, the activity of which is inhibited, resulting in reduced expression of its target genes; mainly inflammatory genes are transrepressed by PPAR $\alpha$ ), with approximately $50 \%$ conservation between mice and humans in terms of gene ontology categories ${ }^{80}$. This conservation across species is particularly relevant when it comes to drug development and translation of pre-clinical data into clinical studies.

These aspects of PPAR $\alpha$ physiology are all relevant to NASH pathogenesis, and pre-clinical data point to an important role for alterations in PPAR $\alpha$, deficiency of which leads to moresevere NASH lesions ${ }^{112}$, which PPAR $\alpha$ agonists prevent or improve ${ }^{97,113}$. Mice with a PPAR $\alpha$ mutant that only has transrepressive activity are protected against the development of NASH but not steatosis, whereas mice with wild-type PPAR $\alpha$ are protected from both NASH and steatosis ${ }^{104}$. Clinical data are in line with these experimental findings, showing that liver PPAR $\alpha$ expression inversely correlates with NASH severity and that improvement of liver histology positively correlates with increased hepatic PPAR $\alpha$ expression ${ }^{91}$.

$\mathrm{PPAR} \beta / \delta$ also has an important role in liver metabolism. Encoded by NR1C2 on human chromosome 6, it is expressed in hepatocytes, sinusoidal endothelial cells, HSCs and Kupffer cells $^{79}$. PPAR $\beta / \delta$ activates pathways of glucose utilization and de novo lipogenesis in the liver. In PPAR $\beta / \delta$-null mice, transcriptional profiling has revealed a downregulation of genes associated with lipoprotein metabolism and glucose utilization pathways, indicating that these genes are positively regulated by PPAR $\beta / \delta^{106}$. In addition, PPAR $\beta / \delta$ increases the production of monounsaturated fatty acids and protects against lipotoxicity and saturated fatty acid cytotoxicity in an in vitro setting ${ }^{114}$. Although PPAR $\beta / \delta$ and PPAR $\alpha$ are both implicated in the fasting and fed state, PPAR $\alpha$ seems to be predominantly important in the fasting state whereas PPAR $\beta / \delta$ is more equally involved in both ${ }^{115}$. Synthetic PPAR $\beta / \delta$ ligands can mimic natural activation of PPAR $\beta / \delta$ pathways, although a differential response might be seen in response to different ligands ${ }^{116}$, as has been reported for other PPAR ligands, which has 
been attributed to the different capacities of these ligands to recruit various coactivators or corepressors $^{117}$.

\section{[H2] Key inflammatory regulators}

All three PPARs participate in the regulation of the inflammatory process, a key component in the development of NASH (Fig. 3). PPAR $\gamma$, which is encoded by NR1C3 on human chromosome 3 , binds to the p65 component of the NF- $\kappa B$ complex and induces inhibitory

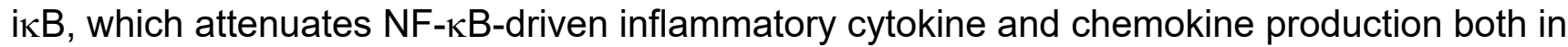
the liver and elsewhere ${ }^{118}$. Upon ligand stimulation, PPAR $\gamma$ promotes the M2 antiinflammatory macrophage phenotype by upregulating CD206 and CD163 ${ }^{119}$. In addition, PPAR $\gamma$ improves endothelial cell function by lowering inflammation in patients with diabetes and atherosclerosis ${ }^{120}$, has a substantial role in controlling vascular homeostasis and decreases blood pressure in patients with T2DM, thereby decreasing risk of CVD ${ }^{121,122}$.

PPAR $\alpha$ also has anti-inflammatory properties, mainly through transrepression of proinflammatory target genes ${ }^{123}$. In humans, this transrepression occurs not only in the liver but also in isolated vascular endothelial cells, linking PPAR $\alpha$ to systemic inflammation and atherosclerosis ${ }^{118,124}$.

PPAR $\beta / \delta$ is highly expressed in hepatocytes, liver sinusoidal endothelial cells and hepatic macrophages including Kupffer cells both in rodents and humans ${ }^{73,125-127}$. It modulates expression of key genes involved in innate immunity and inflammation ${ }^{106}$, although its role in inflammation is incompletely understood. Unligated PPAR $\beta / \delta$ has pro-inflammatory effects mainly in atherosclerotic models, and its ligand engagement disrupts PPAR $\beta / \delta$-corepressor complexes and has anti-inflammatory effects, including suppression of pro-inflammatory adhesion molecules on vascular endothelial cells ${ }^{128-130}$. Ligand binding to PPAR $\beta / \delta$ drives Kupffer cells towards a more anti-inflammatory phenotype ${ }^{131}$. This contributes to hepatic insulin resistance and NASH in mice ${ }^{132}$. Conversely, increasing PPAR $\beta / \delta$ leads to alternatively activated Kupffer cells that have anti-inflammatory properties and results in less severe metabolic and hepatic derangements ${ }^{131}$ (Figure 3).

\section{[H2] Fibrosis regulation}

Fibrosis is the strongest predictor of adverse clinical outcomes in NASH, including liverrelated death and overall mortality ${ }^{133,134}$. Fibrogenesis in HSCs is inhibited by PPARs ${ }^{135}$. PPAR $\gamma$ normally maintains HSCs in a quiescent state, and its overexpression decreases their myofibroblastic character, resulting in reduced collagen production. Reduced expression of PPAR $\gamma$ results in progression of liver fibrosis and increased collagen production ${ }^{99}$. PPAR $\gamma$ and PPAR $\beta / \delta$ are expressed in a stimulus-dependent and tissue-dependent manner in macrophages ${ }^{136}$, which are a key factor for fibrosis, as inflammatory macrophages activate (whereas restorative macrophages deactivate) $\mathrm{HSCs}^{137}$. PPAR $\beta / \delta$ activation in fibroblasts with increased $\alpha$-smooth muscle actin production and myofibroblast differentiation improves wound healing in skin diseases and myocardial infarction through regulation of IL-1 signalling ${ }^{138,139}$.

Human liver PPAR $\alpha$ gene expression negatively correlates with NASH severity, visceral adiposity and insulin resistance ${ }^{91}$. Interestingly, transcriptomic analysis of liver biopsy samples from patients with obesity and NASH before and after bariatric surgery combined with transcriptomic datasets from mice models of NASH and fibrosis identified common clusters of genes with specific functions in inflammation and extracellular matrix homeostasis and in particular a role for PPAR $\alpha$-regulated dermatopontin in NASH-related fibrogenesis ${ }^{140}$. 
Dermatopontin is a protein involved in fibrogenesis and collagen deposition and its expression is lowered by PPAR $\alpha$ activation ${ }^{140,141 .}$

\section{[H2] Non-hepatic tissue in NASH}

PPARs, in particular PPAR $\gamma$, have a key role in adipocyte biology and adaptation to nutrient supply ${ }^{142,143}$. PPAR $\gamma$ is highly expressed in adipose tissue, where it has an essential role in the regulation of adipocyte differentiation, adipogenesis and lipid metabolism ${ }^{56}$. As with the other PPARs, its distribution and actions are complex, and differ also for its two subtypes. PPAR $\gamma 1$ is widely distributed in skeletal and cardiac muscle and the vascular bed, as well as in macrophages, colon epithelium and adipose tissue, whereas PPAR 2 is predominantly expressed in adipose tissue ${ }^{78}$.

In central obesity in humans, there is a switch in gene expression within adipocytes to a pattern that more closely resembles that of macrophages ${ }^{47}$. Thus, excess lipid storage associated with obesity promotes adipose tissue inflammation. In obesity, there is also an increased flux of free fatty acids from adipose tissue to the liver and to other organs, as well as an increase in secretion of proinflammatory adipokines ${ }^{144}$. The combination of altered adipokine secretion and increased flux of free fatty acids promotes the development of ectopic triglyceride accumulation and an increase in the synthesis of toxic lipid mediators in tissues other than adipose, such as liver, muscle and possibly pancreas ${ }^{145}$.

Interventions that reduce fat mass or adipocyte hypertrophy (weight loss) or pharmacologically improve the insulin sensitivity of adipose tissue (such as thiazolidinediones (TZDs)) $)^{28,146-148}$ restore adipose tissue biology and are beneficial in NAFLD given the dynamic crosstalk between the liver and adipose tissue, which adapts to day-to-day changes in energy needs. In humans, at least two-thirds of fatty acids reaching the liver are released from subcutaneous fat ${ }^{47}$. In NAFLD, there is a strong linear relationship between the severity of adipose tissue insulin resistance and that of hepatic steatosis ${ }^{44}$, and patients with steatohepatitis tend to have worse insulin resistance than those with isolated steatosis ${ }^{149}$. However, once patients have developed steatosis, this is closely associated with severe hepatic and muscle insulin resistance, atherogenic dyslipidaemia (elevated triglycerides and low HDL-C), and even hepatocyte necroinflammation ${ }^{44}$.

\section{[H1] PPAR-targeted treatment for NASH}

\section{[H2] PPAR agonist effects on liver}

Owing to their key role in the transcriptional regulation of glucose and lipid metabolism, PPAR ligands hold promise as therapeutic agents for NAFLD ${ }^{56}$. Despite pre-clinical rationale ${ }^{150}$, clinical data on PPAR $\alpha$ single agonists are scarce. The PPAR $\alpha$ agonist fenofibrate reduces lipid levels by activating PPAR $\alpha$, which is highly expressed in the liver, but has no effect on insulin sensitivity ${ }^{151}$ or magnetic resonance imaging (MRI)-assessed hepatic steatosis ${ }^{152}$. Rodents and humans differ substantially in terms of the differential expression and roles of the different PPAR isotypes ${ }^{76,85-87,153}$, which might in part explain why pre-clinical data on the efficacy of isolated PPAR $\alpha$ agonism ${ }^{150}$ have not to date been translated into histological improvement in patients with $\mathrm{NASH}$. As receptor binding and subsequent effects might substantially differ between ligands (which is known as the selective PPAR modulator concept ${ }^{154}$ ), studies are ongoing with other compounds. In a controlled prospective study of 46 patients with $\mathrm{NASH}$, the PPAR $\alpha$ agonist gemfibrozil was shown to improve lipid profiles ${ }^{155,56}$. Pemafibrate, which also showed benefits in terms of liver enzymes and liver histology in pre-clinical NAFLD models and in patients with diabetes and dyslipidaemia, is currently under clinical investigation for NAFLD treatment ${ }^{156-158}$ (Table 2). 
PPAR $\gamma$ activation by TZDs in humans is associated with a broad spectrum of metabolic effects in great part derived from restoring adipose tissue biology ${ }^{47,159}$ and with a decrease in chronic systemic inflammation ${ }^{142,143}$, changes that are strongly associated with an improvement in liver histology in patients with $\mathrm{NASH}^{160}$. In patients with biopsy-proven $\mathrm{NASH}$, rosiglitazone improves hepatic steatosis and serum alanine aminotransferase (ALT) levels, but not other histological features of $\mathrm{NASH}$, including fibrosis after 1 year ${ }^{161}$ or 2 years ${ }^{162}$ of therapy. In rat models of fibrosis, pioglitazone prevented choline-deficient dietinduced fibrosis, but was ineffective once hepatic fibrosis was established ${ }^{163}$. In 55 patients with prediabetes or T2DM, pioglitazone $45 \mathrm{mg}$ once daily for 6 months improved NASH. Mean fibrosis score decreased significantly in the pioglitazone group $(P=0.002)$ but, although this was not the case in the placebo-treated group, the difference in change from baseline between the placebo group and the pioglitazone group did not reach statistical significance $(P=0.08)^{146}$. This trial was followed by an 18 -month randomized controlled trial (RCT) of 101 patients with biopsy-proven NASH, showing a significant treatment benefit in terms of reduction of the NAFLD activity score (NAS) of $\geq 2$ points, resolution of NASH and reduction in mean fibrosis score, along with improvement in metabolic endpoints ${ }^{147}$. In an RCT of 105 patients with T2DM, pioglitazone plus vitamin E improved steatosis, hepatocyte ballooning and inflammation compared with vitamin $E$ alone or placebo ${ }^{164}$. In patients with histologically proven NASH but without diabetes, pioglitazone $30 \mathrm{mg}$ once daily for 12 months was reported to improve hepatic fibrosis ${ }^{148}$, but this was not observed in another study, in which pioglitazone improved all other individual histological parameters except for fibrosis and induced resolution of NASH in $47 \%$ of patients $(n=80)$ compared with $21 \%$ in the placebo arm $(n=83)^{28}$. A meta-analysis indicated that pioglitazone, but not rosiglitazone, significantly reduces fibrosis in patients with $\mathrm{NASH} .{ }^{27}$

Why pioglitazone and rosiglitazone have drastically different efficacy in reversing steatohepatitis remains unclear, but it is often attributed to pioglitazone also being a weak agonist of the PPAR $\alpha$ isotype ${ }^{165}$. However, the action of PPAR $\alpha$ agonists alone seems unlikely to explain the broad effects of pioglitazone on liver histology in NASH. Pioglitazone improves mitochondrial function, for example by downregulation of the tricarboxylic acid cycle flux $^{166}$, but there are many other potential mechanisms by which it might have beneficial effects on the liver (for example, by modulating branched chain amino acid metabolism and decreasing the accumulation of several ceramides) ${ }^{142,143,167,168}$. Evidently, each PPAR $\gamma$ agonist has a unique cardiometabolic signature and biology in the liver.

The PPAR $\alpha / \gamma$ dual agonist saroglitazar has beneficial effects in experimental models of $\mathrm{NASH}^{169}$. A meta-analysis of the use of saroglitazar in patients with diabetic dyslipidaemia in 318 non-invasively diagnosed patients with NAFLD demonstrated that it produced a statistically significant decreases in ALT levels (and liver stiffness in some patients) and improved cardiometabolic profiles ${ }^{170}$; whereas positive results from India on liver histology in patients with biopsy-proven NASH have been announced but not fully released ${ }^{171}$.

Preliminary results of a randomized, double-blind, phase II trial with non-invasive endpoints (EVIDENCES II; NCT03061721) have also been released, showing that it met its primary and secondary endpoints (reduced liver fat, liver enzymes and disease activity on liver histology), but final results have yet to be published ${ }^{172,173}$. The selective PPAR $\beta / \delta$ agonist seladelpar (MBX-8025) improves insulin sensitivity and steatohepatitis in mouse models of NAFLD ${ }^{174}$. In humans, its effect is more on atherogenic dyslipidaemia (for example, a reduction of apolipoprotein B-100 by $20-38 \%$ and LDL cholesterol by $18-43 \%)^{175}$ and is rather modest on insulin sensitivity or steatosis compared with PPAR $\beta / \delta$ agonists. Preliminary results from 171 patients with NASH from a phase II, double-blind RCT ${ }^{176}$, with change in liver fat measured by MRI proton density fat fraction (MRI-PDFF) as the primary endpoint, showed three doses of seladelpar (10 mg, $20 \mathrm{mg}$ and $50 \mathrm{mg}$ ) to be worse than placebo (a 9.8\%, 14.2\% and 13\% reduction versus baseline, respectively, compared with a $20.8 \%$ reduction from baseline with placebo). There was, however, a significant dose-response reduction in ALT and y-glutamyl 
transferase (GGT) levels ${ }^{177}$. The clinical development of seladelpar in liver diseases has, nevertheless, been halted because of atypical findings, including interface hepatitis, in 52week end-of-treatment biopsies in this NASH trial ${ }^{178}$.

In mouse and rat models of NASH and/or liver fibrosis, the dual PPAR $\alpha / \delta$ agonist elafibranor reduced liver fibrosis progression ${ }^{179}$. In a phase Ilb study of 274 patients with biopsy-proven $\mathrm{NASH}$ but not cirrhosis, elafibranor $120 \mathrm{mg}$ once daily was superior to placebo in achieving reversal of $\mathrm{NASH}$ (requiring one of the three components to have a score of 0 ) without worsening of fibrosis $(20 \%$ versus $11 \% ; P=0.018)$ in patients with higher baseline NAS $(\geq 4)^{180}$. Furthermore, in a secondary post-hoc analysis based on a revised definition for the resolution of $\mathrm{NASH}$ requiring the disappearance of ballooning but allowing the persistence of a minor degree of lobular inflammation (a NAS of $\leq 1$ ) without worsening in liver fibrosis (progression by $\geq 1$ stage), this endpoint was met in $19 \%$ of patients receiving elafibranor $120 \mathrm{mg}$ daily $(P=0.045)$ compared to $12 \%$ of patients receiving placebo ${ }^{180}$. Furthermore, patients whose NASH improved also had improved fibrosis. Elafibranor has a positive effect on hepatic and muscle insulin sensitivity ${ }^{181}$, and on steatohepatitis in patients with $\mathrm{NASH}^{180}$. Its efficacy and safety in patients with NASH and fibrosis but no cirrhosis have been evaluated in a phase III trial ${ }^{182}$. Interim results on 717 patients treated with $120 \mathrm{mg}$ of elafibranor for 72 weeks versus 353 placebo-treated patients in intention-to-treat failed to reach the primary histological endpoint of NASH resolution without worsening of fibrosis, but detailed analyses have not been disclosed yet and the trial has been halted ${ }^{183}$.

Activation of PPAR $\beta / \delta$ results in modulation of lipid and glucose homeostasis, skeletal muscle function and brown adipose tissue activity, and PPAR $\beta / \delta$ agonists have been used to successfully treat fibrosis in preclinical animal studies ${ }^{184}$.

\section{[H2] Cardiovascular effects of PPAR agonists}

PPAR $\alpha, P P A R \beta / \delta$ and PPAR $\gamma$ agonists improve endothelial dysfunction and regulate multiple pathways involved in subclinical inflammation and atherosclerosis ${ }^{121,122}$. PPAR $\gamma$ is also highly expressed in atherosclerotic lesions, and its activation reduces inflammatory pathways in cardiomyocytes and in the vascular bed in animal models ${ }^{185-187}$.

The TZDs rosiglitazone and pioglitazone prevent the progression of prediabetes, which affects many patients with NAFLD ${ }^{188}$, to T2DM ${ }^{189,190}$. TZDs also exert longer-lasting glycaemic control than metformin or glibenclamide ${ }^{191}$. Rosiglitazone and pioglitazone increase HDL-C, and rosiglitazone (but not pioglitazone) increases LDL-C and has no effect on plasma triglycerides, which are reduced with pioglitazone treatment ${ }^{192,193}$. This observation might account for the reduction of atherosclerosis progression ${ }^{189,194,195}$ and reduction of CVD risk ${ }^{196-198}$ observed with pioglitazone in patients with T2DM. Moreover, in patients with prediabetes and good adherence to treatment (intake of $\geq 80 \%$ of prescribed dosage; $n=644$ ), pioglitazone reduces stroke by $36 \%$, acute coronary syndromes by $53 \%$, and the combined endpoint of stroke or myocardial infarction or hospitalization for heart failure by $39 \%{ }^{199}$. There is still a misperception that rosiglitazone increases the risk of death from CVD because of a controversial meta-analysis ${ }^{200,201}$. A large RCT found no such increase in the overall risk of cardiovascular morbidity or mortality in people with T2DM treated with rosiglitazone during a mean of 5.5 years of follow up ${ }^{202}$, a conclusion shared in 2013 by the FDA, which led to the removal of regulatory restrictions on rosiglitazone ${ }^{203}$.

Use of the selective PPAR $\beta / \delta$ agonist seladelpar improved the lipid profile of 166 overweight or obese patients with dyslipidaemia and increased risk of CVD ${ }^{204}$, but fibrates (PPAR $\alpha$ agonists) have been more broadly tested in large RCTs and are often associated with reduction in CVD 205,206. Also, dual PPAR $\alpha / \gamma$ agonism by saroglitazar improves cardiovascular risk profile ${ }^{170,207}$. The dual PPAR $\alpha / \delta$ agonist elafibranor improved glycaemic control and lipid profile in patients with $\mathrm{NASH}^{180}$. 


\section{[H2] Pan-PPAR agonists}

Taken together, the concept of combining PPAR $\alpha$, PPAR $\beta / \delta$ and PPAR $\gamma$ activation might represent a novel and potentially more efficacious therapeutic approach by targeting the large array of pathways that contribute to the development and progression of $\mathrm{NASH}^{208}$. Lanifibranor (IVA337) is an indole sulfonamide PPAR agonist that activates all three subtypes, $\alpha, \beta / \delta$ and $\gamma$, giving it the potential to address all the key features of NASH, namely inflammation, steatosis, ballooning and fibrosis ${ }^{209}$. In in vitro and in vivo preclinical studies, lanifibranor prevented and induced the regression of pre-existing fibrotic damage in the liver and other organs, for example skin and lung 210,211, without the classic effects on body weight, fluid retention and increase in heart weight that are reported with TZDs ${ }^{212}$. Lanifibranor also improved insulin sensitivity, diet-induced weight gain, adiposity index and lipid profile - all metabolic features relevant to NASH in diet-induced and genetic models ${ }^{208}$. The effects of lanifibranor on liver histology, proinflammatory and profibrotic gene expression and macrophage accumulation and activation has been shown to be significantly superior to single and dual PPAR agonists in several models of NASH and fibrosis ${ }^{73,213}$ and is being investigated in a double-blind, randomized, placebo-controlled phase $\mathrm{Ilb}$ trial ${ }^{214}$, which is evaluating the efficacy and safety of 24-week lanifibranor treatment compared with placebo in 247 adult patients with NASH with liver steatosis and moderate-to-severe necroinflammation without cirrhosis. Highly significant positive results have been reported for reduction in the activity of steatohepatitis, resolution of NASH, regression of fibrosis and a combination of the latter two (in $31 \%$ of patients on the high dose of $1200 \mathrm{mg}$ versus patients receiving placebo; $P<0.001$ ), along with improvement in glycaemic control and lipid profile and a good safety and tolerability profile ${ }^{215}$. The main clinical outcomes of PPAR agonists are summarized in Table 2.

\section{[H1] Safety profile of PPARs}

In a phase II study of patients with NASH, elafibranor treatment was associated with a slight rise in creatinine ${ }^{180}$. This increase is believed to be due to a rise in renal tubular reabsorption of creatinine, which is related to PPAR $\alpha$ agonism and has been observed with other PPAR $\alpha$ agonists $^{216}$. It is not deleterious to renal function, as demonstrated with fenofibrate, which reduced the progression of chronic kidney disease in patients with T2DM in the large phase III FIELD trial217.

In practice, pioglitazone is the only TZD in use clinically today for the treatment of T2DM. There is increasing recognition of its cardiometabolic benefits ${ }^{199,218,219}$, but it might alter bone metabolism and promote an increase in fractures with long-term use ${ }^{198}$, although the risk remains low and can be monitored and minimized with vitamin $\mathrm{D}$ and calcium supplementation $^{220}$. Haematuria should be checked before and during treatment, although most studies have shown no increased risk of bladder cancer ${ }^{221}$.

A gain of 2-4\% of body weight has been reported after 6-36 months of therapy with pioglitazone in NASH trials ${ }^{28,146-148}$ and in studies of longer duration in patients with T2DM ${ }^{189,196,198}$. These side effects might be treatment-limiting but are reversible upon treatment discontinuation. Furthermore, this weight gain is associated with improved insulin sensitivity by shifting fat from ectopic tissues to subcutaneous and less metabolically deleterious depots, which is consistent with the observed reduction in CVD in RCTs ${ }^{196-198}$. In most patients, weight gain on pioglitazone treatment is exclusively due to an increase in subcutaneous fat and not in visceral fat ${ }^{15,222}$, but peripheral oedema occurs in approximately $5 \%$ of patients, who might require treatment discontinuation.

Pioglitazone reduces the risk of cardiovascular events, but substantial confusion remains regarding its effects on cardiac function. In a phase III trial in 5,238 patients with T2DM patients at high risk of cardiovascular events, that is, who had evidence of macrovascular 
disease at baseline, heart failure was precipitated in $11 \%$ of patients on pioglitazone compared with $8 \%$ of patients receiving placebo, with $1 \%$ experiencing fatal heart failure in both arms. In that same trial, pioglitazone produced a statistically significant reduction in overall mortality and non-fatal cardiovascular events (composite endpoint, 301 out of 2633 patients on pioglitazone versus 358 out of 2633 on placebo, average time of observation 34.5 months, $P=0.027)^{196}$. The increase in the occurrence of heart failure has not been observed in other placebo-controlled studies ${ }^{28,147,189,194,195,198}$. In a large RCT of 3,851 insulin-resistant patients without T2DM, the 5-year heart failure risk did not differ according to treatment $(4.1 \%$ pioglitazone and $4.2 \%$ placebo ${ }^{223}$. While pioglitazone improves whole-body and myocardial insulin sensitivity and left ventricular diastolic and systolic function in healthy patients with T2DM $^{224,225}$, undiagnosed 'diastolic dysfunction' (that is, heart failure with preserved left ventricular function) can occur in $\geq 10 \%$ of patients with longstanding obesity, T2DM and/or $\mathrm{NASH}^{226}$. If fluid retention occurs during pioglitazone therapy in such patients, it might seem to be causing heart failure rather than revealing established but subclinical heart disease. Therefore, in patients with established heart failure or with increased risk of heart failure, pioglitazone is contraindicated. In general, $15 \mathrm{mg}$ per day of pioglitazone is not associated with weight gain $(\sim 1 \%)$, oedema or other side effects and can be the recommended dose for initiation in most patients. Uptitration to $30 \mathrm{mg}$ per day might offer safe and maximal, or nearmaximal, cardiometabolic ${ }^{227}$ and liver histological ${ }^{28,148}$ benefits for patients with NASH. Large RCTs with $15 \mathrm{mg}$ per day of pioglitazone are needed to assess its long-term cardiovascular and histological benefit in NASH.

The dual PPAR $\alpha / \gamma$ agonist saroglitazar has not been associated with weight gain and edema, which have been reported with PPAR $\gamma$ agonists. Indeed, no major serious adverse events have been reported. Long-term cardiovascular safety has not yet been established, but as mentioned, the overall cardiovascular risk factor profile of patients with diabetic dyslipidaemia improves ${ }^{170,228}$. The PPAR $\beta / \delta$ receptor agonist seladelpar, when investigated in a randomized phase II dose-finding study for patients with primary biliary cholangitis, was not associated with drug-induced transaminitis or pruritus ${ }^{229}$, but as mentioned previously, the observation of atypical histological lesions suggestive of interface hepatitis in patients with NASH halted its further development in liver disease.

\section{[H1] Conclusions}

NAFLD is a multisystem disease with extra-hepatic disease implications that include development of T2DM and CVD. Patients with NAFLD often present with many of the features of the metabolic syndrome (for example, central obesity, atherogenic dyslipidaemia, hypertension or abnormal glucose tolerance and insulin resistance), and in progression of liver disease to NASH there is development of hepatic inflammation and often fibrosis. PPARs are key regulators of many of the adversely affected mechanistic pathways involved, which makes PPARs attractive therapeutic targets in the treatment of NASH, not only to benefit the liver but also to ameliorate features of the metabolic syndrome and to attenuate the risk of related extra-hepatic diseases such as T2DM and CVD. Although previous studies have shown limited efficacy of activation of individual PPARs (PPAR $\alpha$ and PPAR $\gamma$ ), ongoing clinical trials suggest that dual and pan-PPAR agonists might have broader and more efficacious therapeutic potential to affect the multisystem disease of NASH by targeting different interrelated mechanisms in the pathophysiology of NASH. 

for the Study of, O. EASL-EASD-EASO Clinical Practice Guidelines for the management of non-alcoholic fatty liver disease. J Hepatol 64, 1388-1402, doi:10.1016/j.jhep.2015.11.004 (2016).

Chalasani, N. et al. The diagnosis and management of nonalcoholic fatty liver disease: practice guidance from the American Association for the Study of Liver Diseases. Hepatology 67, 328-357, doi:10.1002/hep.29367 (2018).

Angulo, P., Machado, M. V. \& Diehl, A. M. Fibrosis in nonalcoholic Fatty liver disease: mechanisms and clinical implications. Semin Liver Dis 35, 132-145, doi:10.1055/s-0035-1550065 (2015). Outcomes. Digestive diseases and sciences 62, 2915-2922, doi:10.1007/s10620-017-4684-x (2017).

Estes, C. et al. Modeling NAFLD disease burden in China, France, Germany, Italy, Japan, Spain, United Kingdom, and United States for the period 2016-2030. J Hepatol 69, 896-904, doi:10.1016/j.jhep.2018.05.036 (2018). An important modelling approach emphasizing the global trends in increasing prevalence of NAFLD and its related morbidity and mortality.

Byrne, C. D. \& Targher, G. NAFLD: a multisystem disease. J Hepato/ 62, S47-64, doi:10.1016/j.jhep.2014.12.012 (2015).

This review cites the evidence that NAFLD has consequences beyond the liver and specifically increases risk of T2DM.

Francque, S. M., van der Graaff, D. \& Kwanten, W. J. Non-alcoholic fatty liver disease and cardiovascular risk: Pathophysiological mechanisms and implications. J Hepatol 65, 425-443, doi:10.1016/j.jhep.2016.04.005 (2016). This review summarizes the mechanisms that link NAFLD to CVD.

Tilg, H., Moschen, A. R. \& Roden, M. NAFLD and diabetes mellitus. Nat Rev Gastroenterol Hepatol 14, 32-42, doi:10.1038/nrgastro.2016.147 (2017).

Lallukka, S. \& Yki-Jarvinen, H. Non-alcoholic fatty liver disease and risk of type 2 diabetes. Best Pract Res Clin Endocrinol Metab 30, 385-395, doi:10.1016/j.beem.2016.06.006 (2016).

Adams, L. A., Anstee, Q. M., Tilg, H. \& Targher, G. Non-alcoholic fatty liver disease and its relationship with cardiovascular disease and other extrahepatic diseases. Gut 66, 1138-1153, doi:10.1136/gutjnl-2017-313884 (2017).

Younossi, Z. M. et al. The global epidemiology of NAFLD and NASH in patients with type 2 diabetes: A systematic review and meta-analysis. J Hepatol, doi:10.1016/j.jhep.2019.06.021 (2019).

Targher, G. \& Byrne, C. D. A Perspective on Metabolic Syndrome and Nonalcoholic Fatty Liver Disease. Metab Syndr Relat Disord 13, 235-238, doi:10.1089/met.2015.1502 (2015).

Francque, S. et al. High prevalence of advanced fibrosis in association with the metabolic syndrome in a Belgian prospective cohort of NAFLD patients with elevated ALT. Results of the Belgian NAFLD registry. Acta Gastroenterol Belg 74, 9-16 (2011).

Gastaldelli, A. \& Cusi, K. From NASH to diabetes and from diabetes to NASH: Mechanisms and treatment options. JHEP Reports 1, 312-328, doi:10.1016/j.jhepr.2019.07.002 (2019).

This review describes the crucial role of dysfunctional adipose tissue in the close relationship between diabetes and NAFLD

Yki-Järvinen, $\mathrm{H}$. Non-alcoholic fatty liver disease as a cause and a consequence of metabolic syndrome. The Lancet Diabetes \& Endocrinology 2, 901-910, doi:10.1016/S2213-8587(14)70032-4 (2014). metabolic syndrome. Int J Mol Sci 17, 367, doi:10.3390/ijms17030367 (2016). 

cardiovascular disease: A meta-analysis. J Hepatol 65, 589-600, doi:10.1016/j.jhep.2016.05.013 (2016).

This meta-analysis cites the evidence that NAFLD is an independent risk factor for incident cardiovascular events.

Sattar, N. et al. Age at diagnosis of type 2 diabetes mellitus and associations with cardiovascular and mortality risks. Circulation 139, 2228-2237, doi:10.1161/CIRCULATIONAHA.118.037885 (2019).

Millett, E. R. C., Peters, S. A. E. \& Woodward, M. Sex differences in risk factors for myocardial infarction: cohort study of UK Biobank participants. BMJ 363, k4247, doi:10.1136/bmj.k4247 (2018).

Stepanova, M., Rafiq, N. \& Younossi, Z. M. Components of metabolic syndrome are independent predictors of mortality in patients with chronic liver disease: a population-based study. Gut 59, 1410-1415, doi:10.1136/gut.2010.213553 (2010).

McPherson, S. et al. Evidence of NAFLD progression from steatosis to fibrosing-steatohepatitis using paired biopsies: implications for prognosis and clinical management. J Hepatol 62, 1148-1155, doi:10.1016/j.jhep.2014.11.034 (2015).

Tada, T. et al. Type 2 diabetes mellitus: A risk factor for progression of liver fibrosis in middle-aged patients with non-alcoholic fatty liver disease. J Gastroenterol Hepatol 34, 2011-2018, doi:10.1111/jgh.14734 (2019).

Yang, J. D. et al. Diabetes is associated with increased risk of hepatocellular carcinoma in patients with cirrhosis from nonalcoholic fatty liver disease. Hepatology, doi:10.1002/hep.30858 (2019).

Angulo, P. et al. Liver fibrosis, but no other histologic features, is associated with long-term outcomes of patients with nonalcoholic fatty liver disease. Gastroenterology 149, 389-397 e310, doi:10.1053/j.gastro.2015.04.043 (2015).

Musso, G., Cassader, M., Paschetta, E. \& Gambino, R. Thiazolidinediones and advanced liver fibrosis in nonalcoholic steatohepatitis: a meta-analysis. JAMA Intern Med 177, 633-640, doi:10.1001/jamainternmed.2016.9607 (2017).

Sanyal, A. J. et al. Pioglitazone, vitamin E, or placebo for nonalcoholic steatohepatitis. N Engl J Med 362, 16751685, doi:10.1056/NEJMoa0907929 (2010).

Armstrong, M. J. et al. Liraglutide safety and efficacy in patients with non-alcoholic steatohepatitis (LEAN): a multicentre, double-blind, randomised, placebo-controlled phase 2 study. Lancet 387, 679-690, doi:10.1016/S0140-6736(15)00803-X (2016).

Francque, S. \& Vonghia, L. Pharmacological Treatment for Non-alcoholic Fatty Liver Disease. Adv Ther 36, 10521074, doi:10.1007/s12325-019-00898-6 (2019).

Konerman, M. A., Jones, J. C. \& Harrison, S. A. Pharmacotherapy for NASH: current and emerging. J Hepatol 68, 362-375, doi:10.1016/j.jhep.2017.10.015 (2018).

Derosa, G., Sahebkar, A. \& Maffioli, P. The role of various peroxisome proliferator-activated receptors and their ligands in clinical practice. Journal of cellular physiology 233, 153-161, doi:10.1002/jcp.25804 (2018).

Targher, G., Lonardo, A. \& Byrne, C. D. Nonalcoholic fatty liver disease and chronic vascular complications of diabetes mellitus. Nat Rev Endocrinol 14, 99-114, doi:10.1038/nrendo.2017.173 (2018).

Haas, J. T., Francque, S. \& Staels, B. Pathophysiology and Mechanisms of Nonalcoholic Fatty Liver Disease. Annu Rev Physiol 78, 181-205, doi:10.1146/annurev-physiol-021115-105331 (2016). Liver Dis 38, 1-13, doi:10.1055/s-0038-1627456 (2018). 

Disease. JAMA Pediatr 170, e161971, doi:10.1001/jamapediatrics.2016.1971 (2016).

Eslam, M. et al. A new definition for metabolic dysfunction-associated fatty liver disease: An international expert consensus statement. J Hepatol, doi:10.1016/j.jhep.2020.03.039 (2020).

Rinella, M. E., Tacke, F., Sanyal, A. J., Anstee, Q. M. \& participants of the, A. E. W. Report on the AASLD/EASL Joint Workshop on Clinical Trial Endpoints in NAFLD. Hepatology, doi:10.1002/hep.30782 (2019).

Samuel, V. T. \& Shulman, G. I. Nonalcoholic fatty liver disease as a nexus of metabolic and hepatic diseases. Cell Metab 27, 22-41, doi:10.1016/j.cmet.2017.08.002 (2018).

Gancheva, S., Jelenik, T., Alvarez-Hernandez, E. \& Roden, M. Interorgan metabolic crosstalk in human insulin resistance. Physiol Rev 98, 1371-1415, doi:10.1152/physrev.00015.2017 (2018).

Jacome-Sosa, M. M. \& Parks, E. J. Fatty acid sources and their fluxes as they contribute to plasma triglyceride concentrations and fatty liver in humans. Curr Opin Lipido/ 25, 213-220, doi:10.1097/MOL.0000000000000080 (2014).

Apostolopoulou, M. et al. Specific hepatic sphingolipids relate to insulin resistance, oxidative stress, and inflammation in nonalcoholic steatohepatitis. Diabetes Care 41, 1235-1243, doi:10.2337/dc17-1318 (2018).

Bril, F. et al. Metabolic and histological implications of intrahepatic triglyceride content in nonalcoholic fatty liver disease. Hepatology 65, 1132-1144, doi:10.1002/hep.28985 (2017).

Dai, W. et al. Prevalence of nonalcoholic fatty liver disease in patients with type 2 diabetes mellitus: A metaanalysis. Medicine (Baltimore) 96, e8179, doi:10.1097/MD.0000000000008179 (2017).

Crewe, C., An, Y. A. \& Scherer, P. E. The ominous triad of adipose tissue dysfunction: inflammation, fibrosis, and impaired angiogenesis. J Clin Invest 127, 74-82, doi:10.1172/JCI88883 (2017).

Cusi, K. Role of obesity and lipotoxicity in the development of nonalcoholic steatohepatitis: pathophysiology and clinical implications. Gastroenterology 142, 711-725 e716, doi:10.1053/j.gastro.2012.02.003 (2012). Reviews the key role of adipose tissue and lipotoxicity in the development of muscle and liver insulin resistance and metabolic syndrome and the rationale for PPAR $y$ insulin sensitizers in NASH.

Diehl, A. M. \& Day, C. Cause, pathogenesis, and treatment of nonalcoholic steatohepatitis. N Engl J Med 377, 2063-2072, doi:10.1056/NEJMra1503519 (2017).

Neuschwander-Tetri, B. A. Hepatic lipotoxicity and the pathogenesis of nonalcoholic steatohepatitis: the central role of nontriglyceride fatty acid metabolites. Hepatology 52, 774-788, doi:10.1002/hep.23719 (2010).

Bessone, F., Razori, M. V. \& Roma, M. G. Molecular pathways of nonalcoholic fatty liver disease development and progression. Cell Mol Life Sci 76, 99-128, doi:10.1007/s00018-018-2947-0 (2019).

Friedman, S. L., Neuschwander-Tetri, B. A., Rinella, M. \& Sanyal, A. J. Mechanisms of NAFLD development and therapeutic strategies. Nat Med 24, 908-922, doi:10.1038/s41591-018-0104-9 (2018).

Tamura, S. \& Shimomura, I. Contribution of adipose tissue and de novo lipogenesis to nonalcoholic fatty liver disease. J Clin Invest 115, 1139-1142, doi:10.1172/JCI24930 (2005).

Roden, M. \& Shulman, G. I. The integrative biology of type 2 diabetes. Nature 576, 51-60, doi:10.1038/s41586019-1797-8 (2019).

This review summarizes the earliest events leading to insulin resistance, ectopic fat deposition and hyperglycaemia in humans and points to the decisive role of dysfunctional adipose tissue.

Donnelly, K. L. et al. Sources of fatty acids stored in liver and secreted via lipoproteins in patients with nonalcoholic fatty liver disease. J Clin Invest 115, 1343-1351, doi:10.1172/JCI23621 (2005).

A classic work describing the contribution of adipose tissue to hepatic steatosis and liver insulin resistance in NAFLD. 

Metabolism 65, 1183-1195, doi:10.1016/j.metabol.2016.04.004 (2016). Gastroenterol Hepatol 15, 349-364, doi:10.1038/s41575-018-0009-6 (2018).

Tacke, F. Targeting hepatic macrophages to treat liver diseases. J Hepatol 66, 1300-1312, doi:10.1016/j.jhep.2017.02.026 (2017).

Jindal, A. et al. Fat-laden macrophages modulate lobular inflammation in nonalcoholic steatohepatitis (NASH). Exp Mol Pathol 99, 155-162, doi:10.1016/j.yexmp.2015.06.015 (2015).

Zhou, Z. et al. Neutrophil-hepatic stellate cell interactions promote fibrosis in experimental steatohepatitis. Cell Mol Gastroenterol Hepatol 5, 399-413, doi:10.1016/j.jcmgh.2018.01.003 (2018).

Grunhut, J. et al. Macrophages in nonalcoholic steatohepatitis: friend or foe? Eur Med J Hepatol 6, 100-109 (2018).

Szabo, G. \& Csak, T. Role of MicroRNAs in NAFLD/NASH. Digestive diseases and sciences 61, 1314-1324, doi:10.1007/s10620-015-4002-4 (2016).

Szabo, G. \& Csak, T. Inflammasomes in liver diseases. J Hepatol 57, 642-654, doi:10.1016/j.jhep.2012.03.035 (2012).

Reviews the role of inflammasome activation in chronic inflammation associated with fibrosis and cirrhosis in liver diseases.

Ganz, M. et al. Progression of non-alcoholic steatosis to steatohepatitis and fibrosis parallels cumulative accumulation of danger signals that promote inflammation and liver tumors in a high fat-cholesterol-sugar diet model in mice. J Transl Med 13, 193, doi:10.1186/s12967-015-0552-7 (2015).

Describes the development of a murine model consisting of a high fat-cholesterol-sugar diet that mimics liver pathology associated with NAFLD progression in humans and characterizes sterile and microbial danger signals associated with inflammation linked to NAFLD disease progression.

Chu, H., Williams, B. \& Schnabl, B. Gut microbiota, fatty liver disease, and hepatocellular carcinoma. Liver Res 2 , 43-51, doi:10.1016/j.livres.2017.11.005 (2018).

Jayakumar, S. \& Loomba, R. Review article: emerging role of the gut microbiome in the progression of nonalcoholic fatty liver disease and potential therapeutic implications. Aliment Pharmacol Ther 50, 144-158, doi:10.1111/apt.15314 (2019).

Marra, F. \& Svegliati-Baroni, G. Lipotoxicity and the gut-liver axis in NASH pathogenesis. J Hepato/ 68, 280-295, doi:10.1016/j.jhep.2017.11.014 (2018).

Krenkel, O. \& Tacke, F. Liver macrophages in tissue homeostasis and disease. Nat Rev Immunol 17, 306-321, doi:10.1038/nri.2017.11 (2017).

Ramachandran, P. et al. Resolving the fibrotic niche of human liver cirrhosis at single-cell level. Nature 575, 512518, doi:10.1038/s41586-019-1631-3 (2019).

Krenkel, O. et al. Myeloid cells in liver and bone marrow acquire a functionally distinct inflammatory phenotype during obesity-related steatohepatitis. Gut 69, 551-563, doi:10.1136/gutjnl-2019-318382 (2020).

This single-cell RNA sequencing analysis of NASH mouse models revealed a striking heterogeneity of myeloid cells and a unique inflammatory polarization of macrophages in NAFLD. 
Reviews the role of inflammatory macrophages in disease severity of NASH and highlights studies of potential treatments for patients with NASH that target macrophage recruitment and polarization.

Lefere, S. et al. Differential effects of selective- and pan-PPAR agonists on experimental steatohepatitis and hepatic macrophages. J Hepatol, doi:10.1016/j.jhep.2020.04.025 (2020).

Dreyer, C. et al. Control of the peroxisomal beta-oxidation pathway by a novel family of nuclear hormone receptors. Cell 68, 879-887, doi:10.1016/0092-8674(92)90031-7 (1992).

Issemann, I. \& Green, S. Activation of a member of the steroid hormone receptor superfamily by peroxisome proliferators. Nature 347, 645-650, doi:10.1038/347645a0 (1990).

Wanders, R. J. \& Waterham, H. R. Biochemistry of mammalian peroxisomes revisited. Annu Rev Biochem 75, 295332, doi:10.1146/annurev.biochem.74.082803.133329 (2006).

Michalik, L. et al. International Union of Pharmacology. LXI. Peroxisome proliferator-activated receptors. Pharmacol Rev 58, 726-741, doi:10.1124/pr.58.4.5 (2006).

Fajas, L. et al. The organization, promoter analysis, and expression of the human PPARgamma gene. J Biol Chem 272, 18779-18789, doi:10.1074/jbc.272.30.18779 (1997).

Tailleux, A., Wouters, K. \& Staels, B. Roles of PPARs in NAFLD: potential therapeutic targets. Biochim Biophys Acta 1821, 809-818, doi:10.1016/j.bbalip.2011.10.016 (2012).

Rakhshandehroo, M., Hooiveld, G., Muller, M. \& Kersten, S. Comparative analysis of gene regulation by the transcription factor PPARalpha between mouse and human. PLoS One 4, e6796, doi:10.1371/journal.pone.0006796 (2009).

de la Rosa Rodriguez, M. A. et al. The whole transcriptome effects of the PPARalpha agonist fenofibrate on livers of hepatocyte humanized mice. BMC Genomics 19, 443, doi:10.1186/s12864-018-4834-3 (2018).

This paper shows the differences between humans and mice in terms of PPAR $\alpha$ activity and target genes.

Roberts, R. A. et al. Apoptosis and proliferation in nongenotoxic carcinogenesis: species differences and role of PPARalpha. Toxicol Lett 112-113, 49-57, doi:10.1016/s0378-4274(99)00243-x (2000).

Holden, P. R. \& Tugwood, J. D. Peroxisome proliferator-activated receptor alpha: role in rodent liver cancer and species differences. J Mol Endocrinol 22, 1-8, doi:10.1677/jme.0.0220001 (1999).

Kersten, S. \& Stienstra, R. The role and regulation of the peroxisome proliferator activated receptor alpha in human liver. Biochimie 136, 75-84, doi:10.1016/j.biochi.2016.12.019 (2017).

Cheung, C. et al. Diminished hepatocellular proliferation in mice humanized for the nuclear receptor peroxisome proliferator-activated receptor alpha. Cancer Res 64, 3849-3854, doi:10.1158/0008-5472.CAN-04-0322 (2004).

Bell, A. R. et al. Molecular basis of non-responsiveness to peroxisome proliferators: the guinea-pig PPARalpha is functional and mediates peroxisome proliferator-induced hypolipidaemia. Biochem J 332 ( Pt 3), 689-693, doi:10.1042/bj3320689 (1998).

Lawrence, J. W. et al. Differential gene regulation in human versus rodent hepatocytes by peroxisome proliferator-activated receptor (PPAR) alpha. PPAR alpha fails to induce peroxisome proliferation-associated genes in human cells independently of the level of receptor expresson. J Biol Chem 276, 31521-31527, doi:10.1074/jbc.M103306200 (2001).

Pap, A., Cuaranta-Monroy, I., Peloquin, M. \& Nagy, L. Is the mouse a good model of human PPARgamma-related metabolic diseases? Int J Mol Sci 17, doi:10.3390/ijms17081236 (2016).

Su, A. I. et al. A gene atlas of the mouse and human protein-encoding transcriptomes. Proc Natl Acad Sci U S A 101, 6062-6067, doi:10.1073/pnas.0400782101 (2004).

Vidal-Puig, A. et al. Regulation of PPAR gamma gene expression by nutrition and obesity in rodents. J Clin Invest 97, 2553-2561, doi:10.1172/JCl118703 (1996). 

patients with non-alcoholic steatohepatitis. J Hepatol 63, 164-173, doi:10.1016/j.jhep.2015.02.019 (2015). and decreasing inflammation during aging. Oncotarget 8, 46273-46285, doi:10.18632/oncotarget.17695 (2017).

Chakravarthy, M. V. et al. Identification of a physiologically relevant endogenous ligand for PPARalpha in liver. Cell 138, 476-488, doi:10.1016/j.cell.2009.05.036 (2009).

Reid, B. N. et al. Hepatic overexpression of hormone-sensitive lipase and adipose triglyceride lipase promotes fatty acid oxidation, stimulates direct release of free fatty acids, and ameliorates steatosis. J Biol Chem 283, 13087-13099, doi:10.1074/jbc.M800533200 (2008).

$\mathrm{Xu}, \mathrm{H}$. E. et al. Structural determinants of ligand binding selectivity between the peroxisome proliferatoractivated receptors. Proc Natl Acad Sci U S A 98, 13919-13924, doi:10.1073/pnas.241410198 (2001).

Braissant, O., Foufelle, F., Scotto, C., Dauca, M. \& Wahli, W. Differential expression of peroxisome proliferatoractivated receptors (PPARs): tissue distribution of PPAR-alpha, -beta, and -gamma in the adult rat. Endocrinology 137, 354-366, doi:10.1210/endo.137.1.8536636 (1996).

Montagner, A. et al. Liver PPARalpha is crucial for whole-body fatty acid homeostasis and is protective against NAFLD. Gut 65, 1202-1214, doi:10.1136/gutjnl-2015-310798 (2016).

Lefebvre, P., Chinetti, G., Fruchart, J. C. \& Staels, B. Sorting out the roles of PPAR alpha in energy metabolism and vascular homeostasis. J Clin Invest 116, 571-580, doi:10.1172/JCI27989 (2006).

Zardi, E. M. et al. Hepatic PPARs: their role in liver physiology, fibrosis and treatment. Curr Med Chem 20, 33703396 (2013).

100 Chen, L. et al. Oleoylethanolamide, an endogenous PPAR-alpha ligand, attenuates liver fibrosis targeting hepatic stellate cells. Oncotarget 6, 42530-42540, doi:10.18632/oncotarget.6466 (2015).

101 Wang, Z. et al. Taurine protected As2O3-induced the activation of hepatic stellate cells through inhibiting PPARalpha-autophagy pathway. Chem Biol Interact 300, 123-130, doi:10.1016/j.cbi.2019.01.019 (2019).

Tardelli, M., Claudel, T., Bruschi, F. V., Moreno-Viedma, V. \& Trauner, M. Adiponectin regulates AQP3 via PPARalpha in human hepatic stellate cells. Biochem Biophys Res Commun 490, 51-54, doi:10.1016/j.bbrc.2017.06.009 (2017).

103 Bougarne, N. et al. Molecular actions of PPARalpha in lipid metabolism and inflammation. Endocr Rev 39, 760802, doi:10.1210/er.2018-00064 (2018).

104 Pawlak, M. et al. The transrepressive activity of peroxisome proliferator-activated receptor alpha is necessary and sufficient to prevent liver fibrosis in mice. Hepatology 60, 1593-1606, doi:10.1002/hep.27297 (2014).

105 Kersten, S. et al. Peroxisome proliferator-activated receptor alpha mediates the adaptive response to fasting. J Clin Invest 103, 1489-1498, doi:10.1172/JCI6223 (1999).

106 Sanderson, L. M., Boekschoten, M. V., Desvergne, B., Muller, M. \& Kersten, S. Transcriptional profiling reveals divergent roles of PPARalpha and PPARbeta/delta in regulation of gene expression in mouse liver. Physiol Genomics 41, 42-52, doi:10.1152/physiolgenomics.00127.2009 (2010).

107 Lemberger, T. et al. Expression of the peroxisome proliferator-activated receptor alpha gene is stimulated by stress and follows a diurnal rhythm. J Biol Chem 271, 1764-1769 (1996).

108 Canaple, L. et al. Reciprocal regulation of brain and muscle Arnt-like protein 1 and peroxisome proliferatoractivated receptor alpha defines a novel positive feedback loop in the rodent liver circadian clock. Mol Endocrinol 20, 1715-1727, doi:10.1210/me.2006-0052 (2006). 
111 Gachon, F. et al. Proline- and acidic amino acid-rich basic leucine zipper proteins modulate peroxisome proliferator-activated receptor alpha (PPARalpha) activity. Proc Natl Acad Sci U S A 108, 4794-4799, doi:10.1073/pnas.1002862108 (2011).

112 Botta, M. et al. PPAR agonists and metabolic syndrome: an established role? Int J Mol Sci 19, doi:10.3390/ijms19041197 (2018).

113 Pawlak, M., Lefebvre, P. \& Staels, B. Molecular mechanism of PPARalpha action and its impact on lipid metabolism, inflammation and fibrosis in non-alcoholic fatty liver disease. J Hepatol 62, 720-733, doi:10.1016/j.jhep.2014.10.039 (2015).

114 Liu, S. et al. Role of peroxisome proliferator-activated receptor $\{$ delta\}/\{beta\} in hepatic metabolic regulation. J Biol Chem 286, 1237-1247, doi:10.1074/jbc.M110.138115 (2011).

115 Liu, S. et al. A diurnal serum lipid integrates hepatic lipogenesis and peripheral fatty acid use. Nature 502, 550554, doi:10.1038/nature12710 (2013).

116 Iwaisako, K. et al. Protection from liver fibrosis by a peroxisome proliferator-activated receptor delta agonist. Proc Natl Acad Sci U S A 109, E1369-1376, doi:10.1073/pnas.1202464109 (2012).

117 Dietz, M. et al. Comparative molecular profiling of the PPARalpha/gamma activator aleglitazar: PPAR selectivity, activity and interaction with cofactors. ChemMedChem 7, 1101-1111, doi:10.1002/cmdc.201100598 (2012).

118 Ricote, M. \& Glass, C. K. PPARs and molecular mechanisms of transrepression. Biochim Biophys Acta 1771, 926935, doi:10.1016/j.bbalip.2007.02.013 (2007).

119 Zizzo, G. \& Cohen, P. L. The PPAR-gamma antagonist GW9662 elicits differentiation of M2c-like cells and upregulation of the MerTK/Gas6 axis: a key role for PPAR-gamma in human macrophage polarization. $\mathrm{J}$ Inflamm (Lond) 12, 36, doi:10.1186/s12950-015-0081-4 (2015).

120 Wilding, J. P. PPAR agonists for the treatment of cardiovascular disease in patients with diabetes. Diabetes Obes Metab 14, 973-982, doi:10.1111/j.1463-1326.2012.01601.x (2012).

121 Han, L., Shen, W. J., Bittner, S., Kraemer, F. B. \& Azhar, S. PPARs: regulators of metabolism and as therapeutic targets in cardiovascular disease. Part I: PPAR-alpha. Future Cardiol 13, 259-278, doi:10.2217/fca-2016-0059 (2017).

122 Han, L., Shen, W. J., Bittner, S., Kraemer, F. B. \& Azhar, S. PPARs: regulators of metabolism and as therapeutic targets in cardiovascular disease. Part II: PPAR-beta/delta and PPAR-gamma. Future Cardiol 13, 279-296, doi:10.2217/fca-2017-0019 (2017).

123 Delerive, P. et al. Peroxisome proliferator-activated receptor alpha negatively regulates the vascular inflammatory gene response by negative cross-talk with transcription factors NF-kappaB and AP-1. J Biol Chem 274, 32048-32054 (1999).

Hou, X. \& Pei, F. Estradiol inhibits cytokine-induced expression of VCAM-1 and ICAM-1 in cultured human endothelial cells via AMPK/PPARalpha activation. Cell Biochem Biophys 72, 709-717, doi:10.1007/s12013-0150522-y (2015).

125 Hoekstra, M., Kruijt, J. K., Van Eck, M. \& Van Berkel, T. J. Specific gene expression of ATP-binding cassette transporters and nuclear hormone receptors in rat liver parenchymal, endothelial, and Kupffer cells. J Biol Chem 278, 25448-25453, doi:10.1074/jbc.M301189200 (2003). (PPARbeta/delta) protein in mice. Biochem Biophys Res Commun 371, 456-461, doi:10.1016/j.bbrc.2008.04.086 (2008). 

activated receptors and liver $X$ receptor-alpha in humans: no alteration in adipose tissue of obese and NIDDM patients. Diabetes 46, 1319-1327, doi:10.2337/diab.46.8.1319 (1997).

128 Fan, Y. et al. Suppression of pro-inflammatory adhesion molecules by PPAR-delta in human vascular endothelial cells. Arterioscler Thromb Vasc Biol 28, 315-321, doi:10.1161/atvbaha.107.149815 (2008).

129 Kilgore, K. S. \& Billin, A. N. PPARbeta/delta ligands as modulators of the inflammatory response. Current opinion in investigational drugs (London, England : 2000) 9, 463-469 (2008).

130 Liu, Y. et al. The Role of PPAR-delta in metabolism, inflammation, and cancer: many characters of a critical transcription factor. Int J Mol Sci 19, doi:10.3390/ijms19113339 (2018).

131 Odegaard, J. I. et al. Alternative M2 activation of Kupffer cells by PPARdelta ameliorates obesity-induced insulin resistance. Cell Metab 7, 496-507, doi:10.1016/j.cmet.2008.04.003 (2008).

132 Lanthier, N. et al. Kupffer cell activation is a causal factor for hepatic insulin resistance. Am J Physiol Gastrointest Liver Physiol 298, G107-116, doi:10.1152/ajpgi.00391.2009 (2010).

133 Dulai, P. S. et al. Increased risk of mortality by fibrosis stage in nonalcoholic fatty liver disease: Systematic review and meta-analysis. Hepatology 65, 1557-1565, doi:10.1002/hep.29085 (2017).

Hagstrom, H. et al. Fibrosis stage but not NASH predicts mortality and time to development of severe liver disease in biopsy-proven NAFLD. J Hepatol 67, 1265-1273, doi:10.1016/j.jhep.2017.07.027 (2017).

Weiskirchen, R., Weiskirchen, S. \& Tacke, F. Organ and tissue fibrosis: molecular signals, cellular mechanisms and translational implications. Mol Aspects Med 65, 2-15, doi:10.1016/j.mam.2018.06.003 (2019).

Lefere, S. \& Tacke, F. Macrophages in obesity and non-alcoholic fatty liver disease: Crosstalk with metabolism. JHEP Reports 1, 30-43, doi:10.1016/j.jhepr.2019.02.004 (2019).

This is an elegant review on the role of macrophages in NAFLD.

137 Ritz, T., Krenkel, O. \& Tacke, F. Dynamic plasticity of macrophage functions in diseased liver. Cell Immunol 330 , 175-182, doi:10.1016/j.cellimm.2017.12.007 (2018).

Ham, S. A. et al. Ligand-activated PPARdelta upregulates alpha-smooth muscle actin expression in human dermal fibroblasts: A potential role for PPARdelta in wound healing. J Dermatol Sci 80, 186-195, doi:10.1016/j.jdermsci.2015.10.005 (2015).

139 Park, J. R. et al. Effects of peroxisome proliferator-activated receptor-delta agonist on cardiac healing after myocardial infarction. PLoS One 11, e0148510, doi:10.1371/journal.pone.0148510 (2016).

140 Lefebvre, P. et al. Interspecies NASH disease activity whole-genome profiling identifies a fibrogenic role of PPARalpha-regulated dermatopontin. JCI Insight 2, doi:10.1172/jci.insight.92264 (2017).

141 Kato, A. et al. Identification of fibronectin binding sites in dermatopontin and their biological function. $J$ Dermatol Sci 76, 51-59, doi:10.1016/j.jdermsci.2014.07.003 (2014).

Soccio, R. E., Chen, E. R. \& Lazar, M. A. Thiazolidinediones and the promise of insulin sensitization in type 2 diabetes. Cell Metab 20, 573-591, doi:10.1016/j.cmet.2014.08.005 (2014).

143 Ma, X., Wang, D., Zhao, W. \& Xu, L. Deciphering the roles of PPARgamma in adipocytes via dynamic change of transcription complex. Front Endocrinol (Lausanne) 9, 473, doi:10.3389/fendo.2018.00473 (2018). (2011). cardiovascular disease. Arterioscler Thromb Vasc Biol 34, 1155-1161, doi:10.1161/ATVBAHA.114.303034 (2014). 

prediabetes or T2DM.

148 Aithal, G. P. et al. Randomized, placebo-controlled trial of pioglitazone in nondiabetic subjects with nonalcoholic steatohepatitis. Gastroenterology 135, 1176-1184, doi:10.1053/j.gastro.2008.06.047 (2008).

149 Lomonaco, R. et al. Metabolic impact of nonalcoholic steatohepatitis in obese patients with type 2 diabetes. Diabetes Care 39, 632-638, doi:10.2337/dc15-1876 (2016).

A study that dissects the relative contribution of adipose tissue, hepatic and muscle insulin resistance in patients with and without diabetes and simple steatosis versus NASH.

150 Larter, C. Z. et al. Peroxisome proliferator-activated receptor-alpha agonist, Wy 14,643, improves metabolic indices, steatosis and ballooning in diabetic mice with non-alcoholic steatohepatitis. J Gastroenterol Hepatol 27, 341-350, doi:10.1111/j.1440-1746.2011.06939.x (2012).

151 Belfort, R., Berria, R., Cornell, J. \& Cusi, K. Fenofibrate reduces systemic inflammation markers independent of its effects on lipid and glucose metabolism in patients with the metabolic syndrome. J Clin Endocrinol Metab 95, 829-836, doi:10.1210/jc.2009-1487 (2010).

152 Fabbrini, E. et al. Effect of fenofibrate and niacin on intrahepatic triglyceride content, very low-density lipoprotein kinetics, and insulin action in obese subjects with nonalcoholic fatty liver disease. J Clin Endocrinol Metab 95, 2727-2735, doi:10.1210/jc.2009-2622 (2010).

153 Palmer, C. N., Hsu, M. H., Griffin, K. J., Raucy, J. L. \& Johnson, E. F. Peroxisome proliferator activated receptoralpha expression in human liver. Mol Pharmacol 53, 14-22 (1998).

Fruchart, J. C. et al. The selective peroxisome proliferator-activated receptor alpha modulator (SPPARMalpha) paradigm: conceptual framework and therapeutic potential : A consensus statement from the International Atherosclerosis Society (IAS) and the Residual Risk Reduction Initiative (R3i) Foundation. Cardiovasc Diabetol 18, 71, doi:10.1186/s12933-019-0864-7 (2019).

155 Basaranoglu, M., Acbay, O. \& Sonsuz, A. A controlled trial of gemfibrozil in the treatment of patients with nonalcoholic steatohepatitis. J Hepatol 31, 384, doi:10.1016/s0168-8278(99)80243-8 (1999).

156 Honda, Y. et al. Pemafibrate, a novel selective peroxisome proliferator-activated receptor alpha modulator, improves the pathogenesis in a rodent model of nonalcoholic steatohepatitis. Sci Rep 7, 42477, doi:10.1038/srep42477 (2017).

157 Araki, E. et al. Efficacy and safety of pemafibrate in people with type 2 diabetes and elevated triglyceride levels: 52-week data from the PROVIDE study. Diabetes Obes Metab 21, 1737-1744, doi:10.1111/dom.13686 (2019).

158 Yokote, K. et al. Long-term efficacy and safety of pemafibrate, a novel selective peroxisome proliferatoractivated receptor-alpha modulator (SPPARMalpha), in dyslipidemic patients with renal impairment. Int J Mol Sci 20, doi:10.3390/ijms20030706 (2019).

159 Maeda, N. et al. PPARgamma ligands increase expression and plasma concentrations of adiponectin, an adiposederived protein. Diabetes 50, 2094-2099 (2001).

160 Gastaldelli, A. et al. Pioglitazone in the treatment of NASH: the role of adiponectin. Aliment Pharmacol Ther 32, 769-775, doi:10.1111/j.1365-2036.2010.04405.x (2010).

161 Ratziu, V. et al. Rosiglitazone for nonalcoholic steatohepatitis: one-year results of the randomized placebocontrolled Fatty Liver Improvement with Rosiglitazone Therapy (FLIRT) Trial. Gastroenterology 135, 100-110, doi:10.1053/j.gastro.2008.03.078 (2008). 

of hepatic fibrosis in rats. Gut 55, 1020-1029, doi:10.1136/gut.2005.079194 (2006).

164 Bril, F. et al. Role of oral vitamin E for the treatment of nonalcoholic steatohepatitis (NASH) in patients with type 2 diabetes: A randomized controlled trial. Diabetes Care, (in press) (2019).

165 Sakamoto, J. et al. Activation of human peroxisome proliferator-activated receptor (PPAR) subtypes by pioglitazone. Biochem Biophys Res Commun 278, 704-711, doi:10.1006/bbrc.2000.3868 (2000).

166 Kalavalapalli, S. et al. Pioglitazone improves hepatic mitochondrial function in a mouse model of nonalcoholic steatohepatitis. Am J Physiol Endocrinol Metab 315, E163-e173, doi:10.1152/ajpendo.00023.2018 (2018).

167 Ahmadian, M. et al. PPARgamma signaling and metabolism: the good, the bad and the future. Nat Med 19, 557566, doi:10.1038/nm.3159 (2013).

Devchand, P. R., Liu, T., Altman, R. B., FitzGerald, G. A. \& Schadt, E. E. The pioglitazone trek via human PPAR gamma: From discovery to a medicine at the FDA and beyond. Front Pharmacol 9, 1093, doi:10.3389/fphar.2018.01093 (2018).

Jain, M. R. et al. Dual PPARalpha/gamma agonist saroglitazar improves liver histopathology and biochemistry in experimental NASH models. Liver Int 38, 1084-1094, doi:10.1111/liv.13634 (2018).

Kaul, U. et al. New dual peroxisome proliferator activated receptor agonist-Saroglitazar in diabetic dyslipidemia and non-alcoholic fatty liver disease: integrated analysis of the real world evidence. Cardiovasc Diabetol 18, 80, doi:10.1186/s12933-019-0884-3 (2019).

171 Zydus. Zydus announces regulatory filing of Saroglitazar Magnesium for treatment of NASH with DCGI, Press Release, (Ahmedabad, India), December 5, 2019.

172 Hong, F., Xu, P. \& Zhai, Y. The opportunities and challenges of peroxisome proliferator-activated receptors ligands in clinical drug discovery and development. Int J Mol Sci 19, doi:10.3390/ijms19082189 (2018).

173 US National Library of Medicine, Saroglitazar magnesium in patients with nonalcoholic fatty liver disease and/or nonalcoholic steatohepatitis, <https://ClinicalTrials.gov/show/NCT03061721>(2019)

174 Haczeyni, F. et al. The selective peroxisome proliferator-activated receptor-delta agonist seladelpar reverses nonalcoholic steatohepatitis pathology by abrogating lipotoxicity in diabetic obese mice. Hepatol Commun $\mathbf{1}$, 663-674, doi:10.1002/hep4.1072 (2017).

175 Bays HE, e. a. MBX-8025, a novel peroxisome proliferator receptor-delta agonist: lipid and other metabolic effects in dyslipidemic overweight patients treated with and without atorvastatin. J Clin Endocrinol Metab. 96, 2889-2897. (2011).

176 US National Library of Medicine, A study to evaluate seladelpar in subjects with nonalcoholic steatohepatitis (NASH), <https://ClinicalTrials.gov/show/NCT03551522> (2019)

177 CymaBay Therapeutics. CymaBay Therapeutics reports topline 12-week data from an ongoing phase $2 \mathrm{~b}$ study of seladelpar in patients with nonalcoholic steatohepatitis, Press Release, June 13, 2019.

178 CymaBay Therapeutics. CymaBay Therapeutics halts clinical development of seladelpar, Press Release, November 25, 2019.

179 Staels, B. et al. Hepatoprotective effects of the dual peroxisome proliferator-activated receptor alpha/delta agonist, GFT505, in rodent models of nonalcoholic fatty liver disease/nonalcoholic steatohepatitis. Hepatology 58, 1941-1952, doi:10.1002/hep.26461 (2013).

Ratziu, V. et al. Elafibranor, an agonist of the peroxisome proliferator-activated receptor-alpha and -delta, induces resolution of nonalcoholic steatohepatitis without fibrosis worsening. Gastroenterology 150, 1147-1159 e1145, doi:10.1053/j.gastro.2016.01.038 (2016). 

and peripheral insulin sensitivity in abdominally obese subjects. Diabetes Care 36, 2923-2930, doi:10.2337/dc122012 (2013).

182 US National Library of Medicine, Phase 3 study to evaluate the efficacy and safety of elafibranor versus placebo in patients with nonalcoholic steatohepatitis (NASH), <https://ClinicalTrials.gov/show/NCT02704403>(2020)

GENFIT. GENFIT: Announces results from interim analysis of RESOLVE-IT phase 3 trial of elafibranor in adults with NASH and fibrosis, Press Release, May 11, 2020.

184 McVicker, B. L. \& Bennett, R. G. Novel anti-fibrotic therapies. Front Pharmacol 8, 318, doi:10.3389/fphar.2017.00318 (2017).

185 Vallee, A., Vallee, J. N. \& Lecarpentier, Y. Metabolic reprogramming in atherosclerosis: Opposed interplay between the canonical WNT/beta-catenin pathway and PPARgamma. J Mol Cell Cardiol 133, 36-46, doi:10.1016/j.yjmcc.2019.05.024 (2019).

186 Zhao, N. et al. Enhanced MiR-711 transcription by PPARgamma induces endoplasmic reticulum stress-mediated apoptosis targeting calnexin in rat cardiomyocytes after myocardial infarction. J Mol Cell Cardiol 118, 36-45, doi:10.1016/j.yjmcc.2018.03.006 (2018).

187 Peymani, M., Ghaedi, K., Irani, S. \& Nasr-Esfahani, M. H. Peroxisome Proliferator-Activated Receptor gamma Activity is Required for Appropriate Cardiomyocyte Differentiation. Cell J 18, 221-228, doi:10.22074/cellj.2016.4317 (2016).

188 Ortiz-Lopez, C. et al. Prevalence of prediabetes and diabetes and metabolic profile of patients with nonalcoholic fatty liver disease (NAFLD). Diabetes Care 35, 873-878, doi:10.2337/dc11-1849 (2012).

189 DeFronzo, R. A. et al. Pioglitazone for diabetes prevention in impaired glucose tolerance. N Engl J Med 364, 11041115, doi:10.1056/NEJMoa1010949 (2011).

190 Inzucchi, S. E. et al. Pioglitazone prevents diabetes in patients with insulin resistance and cerebrovascular disease. Diabetes Care 39, 1684-1692, doi:10.2337/dc16-0798 (2016).

191 Kahn, S. E. et al. Glycemic durability of rosiglitazone, metformin, or glyburide monotherapy. N Engl J Med 355, 2427-2443, doi:10.1056/NEJMoa066224 (2006).

192 Chiquette, E., Ramirez, G. \& Defronzo, R. A meta-analysis comparing the effect of thiazolidinediones on cardiovascular risk factors. Arch Intern Med 164, 2097-2104, doi:10.1001/archinte.164.19.2097 (2004).

193 Goldberg, R. B. et al. A comparison of lipid and glycemic effects of pioglitazone and rosiglitazone in patients with type 2 diabetes and dyslipidemia. Diabetes Care 28, 1547-1554, doi:10.2337/diacare.28.7.1547 (2005).

194 Mazzone, T. et al. Effect of pioglitazone compared with glimepiride on carotid intima-media thickness in type 2 diabetes: a randomized trial. JAMA 296, 2572-2581, doi:10.1001/jama.296.21.joc60158 (2006).

195 Nissen, S. E. et al. Comparison of pioglitazone vs glimepiride on progression of coronary atherosclerosis in patients with type 2 diabetes: the PERISCOPE randomized controlled trial. JAMA 299, 1561-1573, doi:10.1001/jama.299.13.1561 (2008).

196 Dormandy, J. A. et al. Secondary prevention of macrovascular events in patients with type 2 diabetes in the PROactive Study (PROspective pioglitAzone Clinical Trial In macroVascular Events): a randomised controlled trial. Lancet 366, 1279-1289, doi:10.1016/s0140-6736(05)67528-9 (2005).

Paradigm-changing study on the ability of a diabetes medication and insulin-sensitizer (pioglitazone) to reduce stroke and myocardial infarction in patients with T2DM.

197 Lincoff, A. M., Wolski, K., Nicholls, S. J. \& Nissen, S. E. Pioglitazone and risk of cardiovascular events in patients with type 2 diabetes mellitus: a meta-analysis of randomized trials. Jama 298, 1180-1188, doi:10.1001/jama.298.10.1180 (2007). 
Landmark study on the ability of pioglitazone to reduce risk of stroke or myocardial infarction compared with placebo in patients with insulin resistance but without diabetes with a recent history of ischaemic stroke or transient ischaemic attack.

199 Spence, J. D. et al. Pioglitazone therapy in patients with stroke and prediabetes: A post hoc analysis of the IRIS randomized clinical trial. JAMA Neurol, doi:10.1001/jamaneurol.2019.0079 (2019).

200 Nissen, S. E. \& Wolski, K. Effect of rosiglitazone on the risk of myocardial infarction and death from cardiovascular causes. N Engl J Med 356, 2457-2471, doi:10.1056/NEJMoa072761 (2007).

201 Hoogwerf, B. J. et al. Perspectives on some controversies in cardiovascular disease risk assessment in the pharmaceutical development of glucose-lowering medications. Diabetes Care 39 Suppl 2, S219-227, doi:10.2337/dcS15-3025 (2016).

202 Home, P. D. et al. Rosiglitazone evaluated for cardiovascular outcomes in oral agent combination therapy for type 2 diabetes (RECORD): a multicentre, randomised, open-label trial. Lancet 373, 2125-2135, doi:10.1016/s0140-6736(09)60953-3 (2009).

This study, which enrolled more than 4,000 patients, found that rosiglitazone does not increase the risk of overall cardiovascular morbidity or mortality compared with other glucose-lowering drugs.

203 U.S. Food and Drug Administration.FDA eliminates the Risk Evaluation and Mitigation Strategy (REMS) for rosiglitazone-containing diabetes medicines, FDA Drug Safety Communication, December 16, 2015.

204 Choi, Y. J. et al. Effects of the PPAR-delta agonist MBX-8025 on atherogenic dyslipidemia. Atherosclerosis 220, 470-476, doi:10.1016/j.atherosclerosis.2011.10.029 (2012).

205 Keech, A. et al. Effects of long-term fenofibrate therapy on cardiovascular events in 9795 people with type 2 diabetes mellitus (the FIELD study): randomised controlled trial. Lancet 366, 1849-1861, doi:10.1016/s01406736(05)67667-2 (2005).

This large study found that fenofibrate statistically significantly reduces total cardiovascular events, primarily less non-fatal myocardial infarctions.

206 Ginsberg, H. N. et al. Effects of combination lipid therapy in type 2 diabetes mellitus. N Engl J Med 362, 15631574, doi:10.1056/NEJMoa1001282 (2010).

Jani, R. H. et al. A multicenter, prospective, randomized, double-blind study to evaluate the safety and efficacy of Saroglitazar 2 and $4 \mathrm{mg}$ compared with placebo in type 2 diabetes mellitus patients having hypertriglyceridemia not controlled with atorvastatin therapy (PRESS VI). Diabetes Technol Ther 16, 63-71, doi:10.1089/dia.2013.0253 (2014).

208 Wettstein, G. et al. The new-generation pan-peroxisome proliferator-activated receptor agonist IVA337 protects the liver from metabolic disorders and fibrosis. Hepatol Commun 1, 524-537, doi:10.1002/hep4.1057 (2017).

209 Boubia, B. et al. Design, synthesis, and evaluation of a novel series of indole sulfonamide peroxisome proliferator activated receptor (PPAR) alpha/gamma/delta triple activators: discovery of lanifibranor, a new antifibrotic clinical candidate. Journal of medicinal chemistry 61, 2246-2265, doi:10.1021/acs.jmedchem.7b01285 (2018).

210 Ruzehaji, N. et al. Pan PPAR agonist IVA337 is effective in prevention and treatment of experimental skin fibrosis. Ann Rheum Dis 75, 2175-2183, doi:10.1136/annrheumdis-2015-208029 (2016).

211 Avouac, J. et al. Pan-PPAR agonist IVA337 is effective in experimental lung fibrosis and pulmonary hypertension. Ann Rheum Dis 76, 1931-1940, doi:10.1136/annrheumdis-2016-210821 (2017).

Stumvoll, M. \& Haring, H. U. Glitazones: clinical effects and molecular mechanisms. Ann Med 34, $217-224$ (2002).

213 Wettstein, G. et al. The new-generation pan-peroxisome proliferator-activated receptor agonist IVA337 protects the liver from metabolic disorders and fibrosis. Hepatology Communications 1, 524-537, doi:10.1002/hep4.1057 (2017).

214 US National Library of Medicine, Phase $2 b$ Study in NASH to Assess IVA337, $<$ https://ClinicalTrials.gov/show/NCT03008070>(2020) 

clinical trial in non-alcoholic steatohepatitis (NASH) Press Release, June 15, 2020.

216 Bonds, D. E. et al. Fenofibrate-associated changes in renal function and relationship to clinical outcomes among individuals with type 2 diabetes: the Action to Control Cardiovascular Risk in Diabetes (ACCORD) experience. Diabetologia 55, 1641-1650, doi:10.1007/s00125-012-2524-2 (2012).

217 Davis, T. M. et al. Effects of fenofibrate on renal function in patients with type 2 diabetes mellitus: the Fenofibrate Intervention and Event Lowering in Diabetes (FIELD) Study. Diabetologia 54, 280-290, doi:10.1007/s00125-010-1951-1 (2011).

218 Lee, M., Saver, J. L., Liao, H. W., Lin, C. H. \& Ovbiagele, B. Pioglitazone for secondary stroke prevention: A systematic review and meta-analysis. Stroke 48, 388-393, doi:10.1161/strokeaha.116.013977 (2017).

219 DeFronzo, R. A., Inzucchi, S., Abdul-Ghani, M. \& Nissen, S. E. Pioglitazone: The forgotten, cost-effective cardioprotective drug for type 2 diabetes. Diab Vasc Dis Res 16, 133-143, doi:10.1177/1479164118825376 (2019).

220 Portillo-Sanchez, P. et al. Effect of pioglitazone on bone mineral density in patients with nonalcoholic steatohepatitis: A 36-month clinical trial. J Diabetes 11, 223-231, doi:10.1111/1753-0407.12833 (2019).

221 Filipova, E., Uzunova, K., Kalinov, K. \& Vekov, T. Pioglitazone and the risk of bladder cancer: A meta-analysis. Diabetes Ther 8, 705-726, doi:10.1007/s13300-017-0273-4 (2017).

Balas, B. et al. Pioglitazone treatment increases whole body fat but not total body water in patients with nonalcoholic steatohepatitis. J Hepatol 47, 565-570, doi:10.1016/j.jhep.2007.04.013 (2007).

223 Young, L. H. et al. Heart failure after ischemic stroke or transient ischemic attack in insulin-resistant patients without diabetes mellitus Tteated with pioglitazone. Circulation 138, 1210-1220, doi:10.1161/circulationaha.118.034763 (2018).

This secondary analysis of the IRIS trial found that pioglitazone did not increase the risk of heart failure.

224 van der Meer, R. W. et al. Pioglitazone improves cardiac function and alters myocardial substrate metabolism without affecting cardiac triglyceride accumulation and high-energy phosphate metabolism in patients with wellcontrolled type 2 diabetes mellitus. Circulation 119, 2069-2077, doi:10.1161/CIRCULATIONAHA.108.803916 (2009).

225 Clarke, G. D. et al. Pioglitazone improves left ventricular diastolic function in subjects with diabetes. Diabetes Care 40, 1530-1536, doi:10.2337/dc17-0078 (2017).

226 Lehrke, M. \& Marx, N. Diabetes mellitus and heart failure. Am J Cardiol 120, S37-s47, doi:10.1016/j.amjcard.2017.05.014 (2017).

227 Defronzo, R. A. et al. Revitalization of pioglitazone: the optimum agent to be combined with a sodium-glucose co-transporter-2 inhibitor. Diabetes Obes Metab 18, 454-462, doi:10.1111/dom.12652 (2016).

228 Munigoti, S. P. \& Harinarayan, C. V. Role of glitazars in atherogenic dyslipidemia and diabetes: two birds with one stone? Indian J Endocrinol Metab 18, 283-287, doi:10.4103/2230-8210.131134 (2014).

229 Hirschfield, G. et al. LBP-002 - Treatment efficacy and safety of seladelpar, a selective peroxisome proliferatoractivated receptor delta agonist, in primary biliary cholangitis patients: 12- and 26-week analysis from an ongoing international, randomized, dose raging phase 2 study. J Hepatol 68, S105-S106, doi:10.1016/S01688278(18)30429-X. (2018).

WHO. Definition, diagnosis and classification of diabetes mellitus and its complications: report of a WHO consultation. Part 1: diagnosis and classification of diabetes mellitus. (World Health Organization, Geneva, 1999). 
233 Alberti, K. G. et al. Harmonizing the metabolic syndrome: a joint interim statement of the International Diabetes Federation Task Force on Epidemiology and Prevention; National Heart, Lung, and Blood Institute; American Heart Association; World Heart Federation; International Atherosclerosis Society; and international association for the Study of Obesity. Circulation 120, 1640-1645, doi:CIRCULATIONAHA.109.192644 [pii];10.1161/CIRCULATIONAHA.109.192644 [doi] (2009).

US National Library of Medicine, A study of pemafibrate in patients with nonalcoholic fatty liver disease (NAFLD), <https://ClinicalTrials.gov/show/NCT03350165> (2019)

Bays, H. E. et al. MBX-8025, a novel peroxisome proliferator receptor-delta agonist: lipid and other metabolic effects in dyslipidemic overweight patients treated with and without atorvastatin. J Clin Endocrinol Metab 96, 2889-2897, doi:10.1210/jc.2011-1061 (2011).

Belfort, R. et al. A placebo-controlled trial of pioglitazone in subjects with nonalcoholic steatohepatitis. $N$ Engl J Med 355, 2297-2307, doi:10.1056/NEJMoa060326 (2006).

Bril, F. et al. Role of vitamin E for nonalcoholic steatohepatitis in patients with type 2 diabetes: a randomized controlled trial. Diabetes Care 42, 1481-1488, doi:10.2337/dc19-0167 (2019).

US National Library of Medicine, Lanifibranor in patients with type 2 diabetes \& nonalcoholic fatty liver disease, $<$ https://ClinicalTrials.gov/show/NCT03459079> (2020)

Sumida, Y. \& Yoneda, M. Current and future pharmacological therapies for NAFLD/NASH. J Gastroentero/ 53, 362-376, doi:10.1007/s00535-017-1415-1 (2018).

\section{Author contributions}

G.S. and S.V. researched data for the article, made a substantial contribution to discussion of content, wrote the article, and reviewed/edited the manuscript before submission. M.F.A., C.D.B., K.C., J.-F.D., M.R., F.M.S. and F.T. made a substantial contribution to discussion of content and reviewed/edited the manuscript before submission.

\section{Competing interests}

S.F. has a senior clinical research mandate from the Fund for Scientific Research (FWO) Flanders (1802154N) and has acted as advisor and/or lecturer for Roche, Gilead, Abbvie, Bayer, BMS, MSD, Janssen, Actelion, Astellas, Genfit, Inventiva, Intercept, Genentech and Galmed. G.S. has received research support from NIAAA (NIH), Gilead, Intercept, Allergan, Genfit, Novartis, SignaBlock, Shire, University of Florida, BMS, Genentech, Takeda, and Vertex. She is a consultant/advisory board member for Allergan, Glympse Bio, Quest Diagnostic, Salix, Innovate Bioparmaceuticals, Alnylam, Zomagen, Novartis, Carlos Foundation, Generon and Terrafirma. She is Editor-in-Chief of Hepatology Communications. M.F.A. is supported by National Institute of Health (NIH)/NIDDK Nonalcoholic Steatohepatitis Clinical Research Network (NASH CRN, U01DK061713, PI: A.M. Diehl); advisor/consultant for Bristol Myers Squibb, NGM Pharma, Inventiva, Taiwan J, Immuron, Prometheus, Novo-Nordisk. Her institution receives research funding for research from NIH/NIDDK, Inventiva, Enyo, Enanta, Allergan, Novartis, Genfit, Intercept, BMS, NGM Parma, Gilead, Conatus, Durect, Poxel, Madrigal, Celgene, Galactin, Galmed, Novo-Nordisk, Taiwan J, Prometheus, TARGET NASH, and Progenity. She serves on speaker's bureau for Simply Speaking NASH, iHEP NASH, PRIME NASH Programming, Clinical Care Options, and Alexion. C.D.B. is supported by the National Institute for Health 
Research (NIHR) through the NIHR Southampton Biomedical Research Centre. He is a consultant for Inventiva. K.C. has received research support for the University of Florida as principal investigator from the NIH, Cirius, Echosens, Inventiva, Novartis, Novo Nordisk, Poxel, TARGET NASH and Zydus. He is a consultant for Allergan, Astra-Zeneca, BMS, Boehringer Ingelheim, Coherus, Eli Lilly, Genentech, Gilead, Janssen, Merck, Pfizer, Poxel, Prosciento, Novo Nordisk, Sanofi-Aventis and TARGET NASH. J.-F.D. is consultant/advisory board member for Abbvie, Allergan, Bayer, Bristol-Myers Squibb, Falk, Genfit, Genkyotex, Gilead Science, HepaRegenix, Intercept Pharma, Lilly, Merck, Novartis. He serves as investigator of studies supported by Abbvie, Bayer, BMS, Falk, Genfit, Gilead Science, Intercept, Inventiva, Lilly, Merck, and Novartis. M.R. has received research support from the Ministry of Culture and Science of the State of North Rhine-Westphalia and the German Federal Ministry of Health, grants from the European Fonds for Regional Development (EFRE0400191), German Research Foundation (DFG, SFB 1116/2) and the Schmutzler Stiftung; serves as investigator of studies supported by Boehringer-Ingelheim Pharma, Nutriticia/Danone and Sanofi; was advisor/consultant for Bristol-Myers Squibb, Eli Lilly, Gilead, Intercept Pharma, Novo Nordisk, Novartis, Poxel, Prosciento, Sanofi, Servier and TARGET NASH. F.S. is a consultant to Pfizer, AstraZeneca, and Abbvie. F.T. has received research funding at Charité University Medicine Berlin from Allergan, BristolMyers Squibb, Galapagos and Inventiva. He is a consultant for Allergan, Bayer, Boehringer Ingelheim, Galapagos, Galmed, Intercept, Inventiva, and Pfizer.

\section{Key points}

- Nonalcoholic steatohepatitis (NASH) is the fastest growing liver disease worldwide; however, it is often not recognized until advanced disease stages.

- $\mathrm{NASH}$, the liver manifestation of the metabolic syndrome, requires a holistic approach for management and treatment.

- Peroxisome proliferator-activated receptors (PPARs) regulate metabolism, inflammation and fibrosis, all of which determine NASH progression.

- There is an urgent need for medical therapy for NASH patients.

- Both PPAR $\alpha-\beta / \delta$ dual agonism as well as PPAR $\gamma$ agonism have shown beneficial effects on liver histology in phase Ilb clinical trials for NASH.

- Single, dual and pan-PPAR agonists are under development for the pharmacological treatment of NASH.

Table 1. Criteria for diagnosing metabolic syndrome

\begin{tabular}{|c|c|c|c|c|}
\hline Criteria & WHO (1999) $)^{230}$ & $\operatorname{NCEP}(2001)^{231}$ & IDF $(2005)^{232}$ & $\begin{array}{c}\text { Joint Societies } \\
(2009)^{233}\end{array}$ \\
\hline $\begin{array}{l}\text { Required for } \\
\text { diagnosis }\end{array}$ & $\begin{array}{l}\text { Impaired glucose tolerance } \\
\text { or diabetes and/or insulin } \\
\text { resistance }\end{array}$ & None & $\begin{array}{l}\text { Central obesity } \\
\text { as defined } \\
\text { below }\end{array}$ & None \\
\hline $\begin{array}{l}\text { Number of } \\
\text { features }\end{array}$ & Two other factors & $\geq 3$ of the below & $\geq 2$ of the below & $\geq 3$ of the below \\
\hline Central obesity & $\begin{array}{l}\text { Waist-hip ratio of }>0.9 \text { in } \\
\text { men, }>0.85 \text { in women or } \\
\text { BMI } \geq 30 \mathrm{~kg} / \mathrm{m}^{2}\end{array}$ & $\begin{array}{l}\text { Waist circumference } \\
\geq 102 \mathrm{~cm} \text { in men, } \\
\geq 88 \mathrm{~cm} \text { in women }\end{array}$ & $\begin{array}{l}\text { Waist } \\
\text { circumference } \geq \\
94 \mathrm{~cm} \\
\text { European men; } \\
\geq 90 \mathrm{~cm} \text { South } \\
\text { Asian or } \\
\text { Chinese men; } \geq \\
80 \mathrm{~cm} \text { women }\end{array}$ & $\begin{array}{l}\text { Waist } \\
\text { circumference - } \\
\text { population- } \\
\text { specific } \\
\text { definitions }\end{array}$ \\
\hline Triglycerides & $\geq 150 \mathrm{mg} / \mathrm{dL}(1.7 \mathrm{mmol} / \mathrm{L})$ & $\begin{array}{l}\geq 150 \mathrm{mg} / \mathrm{dL}(1.7 \\
\mathrm{mmol} / \mathrm{L})\end{array}$ & $\begin{array}{l}\geq 150 \mathrm{mg} / \mathrm{dL} \\
(1.7 \mathrm{mmol} / \mathrm{L}) \text { or } \\
\text { treatment for }\end{array}$ & $\begin{array}{l}\geq 150 \mathrm{mg} / \mathrm{dL}(1.7 \\
\mathrm{mmol} / \mathrm{L}) \text { or } \\
\text { treatment for } \\
\text { high triglycerides }\end{array}$ \\
\hline
\end{tabular}




\begin{tabular}{|c|c|c|c|c|}
\hline & & & $\begin{array}{l}\text { high } \\
\text { triglycerides }\end{array}$ & \\
\hline HDL-cholesterol & $\begin{array}{l}<40 \mathrm{mg} / \mathrm{dL}(1 \mathrm{mmol} / \mathrm{L}) \text { in } \\
\mathrm{men},<50 \mathrm{mg} / \mathrm{dL}(1.3 \\
\mathrm{mmol} / \mathrm{L}) \text { in women }\end{array}$ & $\begin{array}{l}<40 \mathrm{mg} / \mathrm{dL}(1 \\
\mathrm{mmol} / \mathrm{L}) \text { in } \mathrm{men}, \\
<50 \mathrm{mg} / \mathrm{dL}(1.3 \\
\mathrm{mmol} / \mathrm{L}) \text { in women }\end{array}$ & $\begin{array}{l}<40 \mathrm{mg} / \mathrm{dL}(1 \\
\mathrm{mmol} / \mathrm{L}) \text { in men, } \\
<50 \mathrm{mg} / \mathrm{dL}(1.3 \\
\mathrm{mmol} / \mathrm{L}) \text { in } \\
\text { women }\end{array}$ & $\begin{array}{l}<40 \mathrm{mg} / \mathrm{dL}(1 \\
\mathrm{mmol} / \mathrm{L}) \text { in men, } \\
<50 \mathrm{mg} / \mathrm{dL}(1.3 \\
\mathrm{mmol} / \mathrm{L}) \text { in } \\
\text { women }\end{array}$ \\
\hline Hypertension & $\geq 140 / 90 \mathrm{mmHg}$ & $\begin{array}{l}\geq 135 / 85 \mathrm{mmHg} \text { or } \\
\text { treated } \\
\text { hypertension }\end{array}$ & $\begin{array}{l}\geq 135 / 85 \mathrm{mmHg} \\
\text { or treated } \\
\text { hypertension }\end{array}$ & $\begin{array}{l}\geq 135 / 85 \mathrm{mmHg} \\
\text { or treated } \\
\text { hypertension }\end{array}$ \\
\hline Glucose & NA & $\begin{array}{l}110 \mathrm{mg} / \mathrm{dL}(6.1 \\
\mathrm{mmol} / \mathrm{L})\end{array}$ & $\begin{array}{l}\geq 100 \mathrm{mg} / \mathrm{dL} \\
(5.6 \mathrm{mmol} / \mathrm{L}) \text { or } \\
\text { diagnosed with } \\
\text { type } 2 \text { diabetes } \\
\text { mellitus }\end{array}$ & $\begin{array}{l}\geq 100 \mathrm{mg} / \mathrm{dL} \text { (5.6 } \\
\mathrm{mmol} / \mathrm{L}) \text {, or drug } \\
\text { treatment for } \\
\text { diabetes }\end{array}$ \\
\hline Microalbuminuria & $\begin{array}{l}\text { Albumin-creatinine ratio } \\
>30 \mathrm{mg} / \mathrm{g} \text {; albumin } \\
\text { excretion rate }>20 \mu \mathrm{g} / \mathrm{min}\end{array}$ & NA & NA & NA \\
\hline
\end{tabular}

NA, not applicable; NCEP, National Cholesterol Education Program; IDF, International Diabetes Federation.

Table 2: Main clinical outcomes of PPAR agonists

\begin{tabular}{|c|c|c|c|c|c|}
\hline $\begin{array}{l}\text { PPAR } \\
\text { target }\end{array}$ & $\begin{array}{c}\text { PPAR } \\
\text { agonist }\end{array}$ & Action & Effect on liver & Clinical status & Safety profile \\
\hline \multicolumn{6}{|c|}{ Single PPAR agonists } \\
\hline PPAR $\alpha$ & Fibrates & $\begin{array}{l}\text { Enhanced free } \\
\text { fatty acid (FFA) } \\
\text { metabolism; } \\
\text { many } \\
\text { antiatherogenic } \\
\text { effects on } \\
\text { lipoprotein } \\
\text { metabolism: } \\
\downarrow \text { plasma } \\
\text { triglycerides, } \\
\uparrow \text { HDL-C }\end{array}$ & $\begin{array}{l}\text { No effect on } \\
\text { hepatic } \\
\text { steatosis or } \\
\text { nonalcoholic } \\
\text { steatohepatitis } \\
\text { (NASH) }^{151,152}\end{array}$ & $\begin{array}{l}\text { Pemafibrate }{ }^{157,158} \\
\text { in phase II (MRI- } \\
\text { based endpoint) } \\
\text { NCTo3350165 } 5^{234}\end{array}$ & $\begin{array}{l}\text { Toxic liver injury, } \\
\text { impaired renal } \\
\text { function (less } \\
\text { with } \\
\text { pemafibrate) }\end{array}$ \\
\hline PPAR $\gamma$ & Rosiglitazone & $\begin{array}{l}\text { Improved } \\
\text { glucose and } \\
\text { FFA } \\
\text { metabolism; } \\
\uparrow \text { LDL-C and } \\
\text { HDL-C }\end{array}$ & $\begin{array}{l}\text { Reduction of } \\
\text { hepatic } \\
\text { steatosis; no } \\
\text { effect on } \\
\text { resolution of } \\
\text { NASH }\end{array}$ & $\begin{array}{l}\text { Phase II trials } \\
\text { have been } \\
\text { conducted }^{161,162}\end{array}$ & $\begin{array}{l}\text { Weight gain, } \\
\text { fluid retention } \\
\text { and cardiac } \\
\text { decompensation, } \\
\text { bone fractures }\end{array}$ \\
\hline PPARß/ס & Seladelpar & $\begin{array}{l}\text { Improved } \\
\text { FFA/lipid (LDL- } \\
\text { C, TG, HDL-C) } \\
\text { and glucose } \\
\text { metabolism }\end{array}$ & $\begin{array}{l}\text { No effect on } \\
\text { hepatic } \\
\text { steatosis }^{177 *}\end{array}$ & $\begin{array}{l}\text { Phase II (MRI- } \\
\text { based endpoint } \\
\text { at } 12 \text { weeks, } \\
\text { histological } \\
\text { secondary } \\
\text { endpoints at } 52 \\
\text { weeks) }\end{array}$ & $\begin{array}{l}\text { Gastrointestinal } \\
\text { side effects, } \\
\text { headache }\end{array}$ \\
\hline
\end{tabular}




\begin{tabular}{|c|c|c|c|c|c|}
\hline & & & & $\begin{array}{l}\text { (NCT03551522, } \\
\text { suspended }{ }^{176} \text { ) }\end{array}$ & \\
\hline \multicolumn{6}{|c|}{ Dual PPAR agonists } \\
\hline PPAR $\alpha / \gamma$ & Pioglitazone & $\begin{array}{l}\text { Improved } \\
\text { glucose and } \\
\text { FFA } \\
\text { metabolism; } \\
\downarrow \text { plasma } \\
\text { triglycerides, } \\
\uparrow \text { HDL-C, } \\
\text { neutral effect } \\
\text { on LDL-C }\end{array}$ & $\begin{array}{l}\text { Induces } \\
\text { resolution of } \\
\text { NASH }^{55 * *} ;\end{array}$ & $\begin{array}{l}\text { Pioglitazone: five } \\
\text { phase II trials } \\
\text { involving } 498 \\
\text { patients with } \\
\text { NASH have been } \\
\text { conducted } \\
28,147,148,236,237\end{array}$ & $\begin{array}{l}\text { Weight gain, } \\
\text { fluid retention } \\
\text { and cardiac } \\
\text { decompensation } \\
\text { in patients with } \\
\text { pre-existing } \\
\text { reduced cardiac } \\
\text { function } \\
\text { (pioglitazone } \\
\text { improves overall } \\
\text { cardiovascular } \\
\text { outcomes), bone } \\
\text { fractures }\end{array}$ \\
\hline PPAR $\alpha / \gamma$ & Saroglitazar & $\begin{array}{l}\text { Improved } \\
\text { glucose and } \\
\text { FFA } \\
\text { metabolism; } \\
\downarrow \text { plasma } \\
\text { triglycerides; } \\
\uparrow \text { HDL-C; } \\
\text { neutral effect } \\
\text { on LDL-C }\end{array}$ & $\begin{array}{l}\text { Improves ALT } \\
\text { and } \\
\text { steatosis }^{170,238}\end{array}$ & $\begin{array}{l}\text { Phase II with } \\
\text { non-invasive } \\
\text { endpoints and } \\
\text { histology } \\
\text { EVIDENCES II } \\
\left(\text { NCTo3061721, }{ }^{173}\right)\end{array}$ & $\begin{array}{l}\text { Body weight } \\
\text { neutral, gastritis } \\
\text { and dyspepsia }\end{array}$ \\
\hline PPAR $\alpha / \delta$ & Elafibranor & $\begin{array}{l}\text { Improvement } \\
\text { of atherogenic } \\
\text { profile and } \\
\text { FFA/glucose } \\
\text { metabolism }\end{array}$ & $\begin{array}{l}\text { Might induce } \\
\text { resolution of } \\
\mathrm{NASH}^{180} \\
\text { negative interim } \\
\text { results, but full } \\
\text { disclosure of the } \\
\text { results is } \\
\text { pending. }\end{array}$ & $\begin{array}{l}\text { Phase III (with } \\
\text { histological } \\
\text { endpoint at } \\
\text { interim analysis } \\
\text { for conditional } \\
\text { approval) } \\
\text { (NCTo2704403) }^{182} \\
\text { Trial has been } \\
\text { discontinued. }\end{array}$ & $\begin{array}{l}\text { Body weight } \\
\text { neutral; } \\
\text { headache; } \\
\text { increase in } \\
\text { serum creatinine } \\
\text { but no other } \\
\text { markers of } \\
\text { impaired renal } \\
\text { function }\end{array}$ \\
\hline \multicolumn{6}{|c|}{ Pan PPAR agonists } \\
\hline $\begin{array}{l}\text { PPAR } \\
\alpha / \delta / \gamma\end{array}$ & Lanifibranor & $\begin{array}{l}\text { Improved } \\
\text { glucose and } \\
\text { FFA } \\
\text { metabolism; } \\
\downarrow \text { plasma } \\
\text { triglycerides; } \\
\uparrow \text { HDL-C; } \\
\text { neutral effect } \\
\text { on LDL-C }\end{array}$ & $\begin{array}{l}\text { Lowering of } \\
\text { ALT208; } \\
\text { positive results } \\
\text { on histology } \\
\text { with significant } \\
\text { benefit over } \\
\text { placebo for } \\
\text { resolution of } \\
\text { steatohepatitis, } \\
\text { regression of } \\
\text { fibrosis and } \\
\text { the } \\
\text { combination of } \\
\text { both } 215\end{array}$ & $\begin{array}{l}\text { Phase II } \\
\text { (histological } \\
\text { endpoint) } \\
\text { NCTo3459079 }\end{array}$ & $\begin{array}{l}\text { Headache, } \\
\text { dizziness }\end{array}$ \\
\hline
\end{tabular}

${ }^{*}$ No liver biopsy data available for seladelpar in NASH (ongoing studies).

**Liver biopsy data only available for pioglitazone, not saroglitazar (ongoing studies). 
Figure 1. Relationships between NAFLD, T2DM and metabolic syndrome, CVD and HCC. This figure schematically describes the relationships between nonalcoholic fatty liver disease (NAFLD), type 2 diabetes mellitus (T2DM) and metabolic syndrome, cardiovascular disease (CVD) and hepatocellular carcinoma (HCC). NAFLD is associated with features of the metabolic syndrome (such as central obesity, atherogenic dyslipidaemia, hyperglycaemia and hypertension). NAFLD increases the risk of T2DM ${ }^{18}$ and CVD ${ }^{19}$. With the development of T2DM there is a further increase in risk of CVD ${ }^{20,21}$, a worsening of liver disease (fibrosis and cirrhosis $)^{22-24}$ and increased risk of $\mathrm{HCC}^{25}$. Development of advanced liver fibrosis with NAFLD also increases risk of CVD ${ }^{26}$.

Figure 2. The role of PPARs in NASH and fibrosis development. The development of nonalcoholic steatohepatitis (NASH), starting from isolated steatosis to steatohepatitis accompanied by necroinflammation and then leading to the development of fibrosis, cirrhosis and vascular injury, is an interplay between all the different cells present within the liver (such as hepatocytes, infiltrating macrophages, Kupffer cells, hepatic stellate cells (HSCs) and liver sinusoidal endothelial cells) and surrounding organs such as the adipose tissue, intestine and skeletal muscle. Peroxisome proliferator-activated receptors (PPARs), composed of three different isotypes ( $\alpha, \beta / \delta$ and $\gamma$ ) are implicated in regulating lipids and carbohydrate metabolism. In NASH, PPARa could improve lipid metabolism by controlling lipid flux and regulating fatty acid transport as well as $\beta$-oxidation. It also reduces inflammation through its action on hepatocytes as well as reducing splanchnic inflammation and intestinal permeability. PPARa is also involved in decreasing portal pressure in the context of cirrhosis. $\mathrm{PPAR} \beta / \delta$ is also involved in glucose and lipoprotein metabolism and reduces insulin resistance in skeletal muscle. Furthermore, PPAR $\beta / \delta$ inhibits inflammatory macrophage phenotypes and favours the alternatively activated phenotype. PPAR $\gamma$ regulates insulin sensitivity within the adipose tissue and is a master regulator of HSC fate. PPAR $\gamma$ prevents HSC activation, which is a key event in fibrogenesis. Moreover, in the context of cirrhosis, PPAR $\gamma$ reduces portal pressure, splanchnic inflammation, angiogenesis and porto-systemic shunts. Together, the three PPAR isotypes act in different cells and organs and therefore influence different pathways and mechanisms involved in NASH and fibrosis progression. This figure is based on publications presenting animal models and human data. Thus, they should be interpreted with caution from a translational perspective ${ }^{32,208,240}$. FFAs, free fatty acids; HCC, hepatocellular carcinoma; PDGF, platelet-derived growth factor; ROS, reactive oxygen species; TG, triglyceride; TGF, transforming growth factor; TNF, tumour necrosis factor.

Figure 3. PPARs and inflammation. a | Peroxisome proliferator-activated receptors (PPARs) as nuclear regulators. PPARs form a complex with the retinoid $X$ receptor (RXR) that activates expression of the PPAR response element (PPRE), which promotes transactivating effects (lipid metabolism, glucose homeostasis and cell differentiation). Alternatively, PPARs can also function as trans-repressors through inhibition of nuclear factor- $\mathrm{kB}$ (NF-kB), activator protein 1 (AP-1), signal transducer and activator of transcription (STAT) or nuclear factor of activated T cells (NFAT) to induce anti-inflammatory effects. b | PPAR-mediated regulation of inflammation. PPAR $\alpha$ regulates inflammation via increasing expression of LTB4-catabolizing enzymes that inhibit extracellular leukotriene B4 (LTB4)mediated inflammation, preventing NF-kB-mediated increases in IL-6 and IL-12 expression

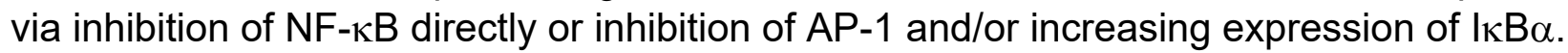


Additionally, PPAR $\alpha$ and PPAR $\beta / \delta$ inhibit vascular cell adhesion molecule 1 (VCAM1) expression via inhibition of tumour necrosis factor receptor (TNFR)-mediated activation of NF- $\kappa$ B. Boxes are colour-coded to indicate the effects of specific PPARs. Green, yellow and orange boxes indicate effects of PPAR $\alpha, \operatorname{PPAR} \beta / \delta$ and PPAR $\gamma$, respectively. PPAR $\gamma$ inhibits $\mathrm{NF}-\kappa \mathrm{B}-$ mediated macrophage survival and increased expression of iNOS, pro-inflammatory chemokines and cytokines via direct inhibition of TLR-mediated or TNFR-mediated activation of NF- $\mathrm{B}$ and inhibition of TLR-mediated activation of AP-1. iNOS, inducible NO synthase; IKB, inhibitory subunit of NFKB; LPS, lipopolysaccharide; TLR, Toll-like receptors.

\section{Box 1 | Suggested lifestyle interventions to improve liver histology in NASH}

[H1] Energy restriction

- 500-1000 kcal energy deficit

- $7-10 \%$ total weight loss target

- Long-term maintenance approach

[H1] Nutrition

- Mediterranean diet

- Avoid fructose

- Low-to-moderate fat

- Moderate-to-high carbohydrate

- Low-carbohydrate ketogenic diets or high protein

[H1] Alcohol intake

- Strictly keep alcohol below the risk threshold (30 g/day for men; $20 \mathrm{~g} /$ day for women)

[H1] Exercise and physical activity

- Moderate intensity aerobic physical activities (150-200 $\mathrm{min} /$ week)

- 3-5 sessions

- Resistance training

Diet and lifestyle changes are mandatory in all patients ${ }^{2,3}$. 